\title{
What Users Want: the Factors that Determine the Retention of Social Location-Based Services
}

\author{
Shu-Chun Ho \\ Graduate Institute of Information and Computer Education \\ National Kaohsiung Normal University, Taiwan \\ No.116, Heping 1st Rd., Lingya District, \\ Kaohsiung 802, Taiwan \\ sch@nknu.edu.tw \\ Jian-Liang Chen \\ Department of Information Management \\ National Penghu University of Science and Technology \\ No.300, Liuhe Rd., Magong City, \\ Penghu County 880, Taiwan \\ jacoblight@npu.edu.tw \\ Sheng-Tsz Luo \\ Graduate Institute of Information and Computer Education \\ National Kaohsiung Normal University, Taiwan \\ No.116, Heping 1st Rd., Lingya District, \\ Kaohsiung 802, Taiwan \\ osa90235@gmail.com
}

\begin{abstract}
The ever increasing technological capabilities of mobile phones and the popularity of social network services (SNS) create new opportunities for Social Location-based Service (SLBS). SLBS refers to software applications that allow users of mobile devices to position themselves and access social network services in real time and a ubiquitous manner. The changing behavior of current consumers calls for the need to understand consumer behavior with new theoretical perspectives within the SLBS context. The objective of this paper is to investigate the critical factors that affect consumers' satisfaction and continued use of SLBS. Based on Expectation Confirmation Theory (ECT), we consider the features of SLBS to examine performance, expectation, satisfaction, and continuance of SLBS. This research is derived from survey data provided by 464 SLBS users. Structural equation modeling (SEM) was performed to empirically test the proposed model. The results show that SLBS performance, SLBS confirmation, and social network confirmation all contribute to the satisfaction and continuance of SLBS. Our findings provide practical and theoretical insights that explain the factors that influence the satisfaction and continuance of SLBS.
\end{abstract}

Keywords: Expectation confirmation theory, social location-based service (SLBS), mobile devices, social network services 


\section{Introduction}

Continuous advances in mobile device technology and the almost universal adoption of social network services (SNS) have transformed consumer behavior dramatically (Kleijen et al., 2009; Constantiou et al. 2014; Wang and Wu, 2014). Mobile device manufacturers and social network service providers have endeavored to embed location-based services into their devices and services. A social location-based service (SLBS) allows users to "check in" locations in order to connect with friends, access promotional discounts, or participate in special offers from retailers. Specifically, SLBSs are defined as software applications that allow mobile device users to position themselves and access social network services in real time and a ubiquitous manner. Social network sites such as Facebook, Myspace, Twitter, Linkedln, and Plurk have endeavored to create new business models by offering SLBS. One of the most popular SLBS examples is "check-in", offered by Facebook. Social network sites such as, Foursquare and Yelp allow users to synchronize their position with the physical location of a business thereby enhancing the available geo-specific information. This allows for more informed decisions regarding where to eat, sleep, shop, and relax. SLBS offer advantageous personalized and context-aware services for a user's social networks on the basis of the user's current location (Dhar and Varshney, 2011; Krishnamurthy and Pelechrinis, 2013). The ubiquity of information access has created new business opportunities for SLBS. Delineating the factors that enhance and reduce users' satisfaction and their decision to continue using specific SLBS applications is integral to strategic planning of the engineers that develop applications that utilize SLBS and the businesses or community services that integrate these applications into their communications strategies.

Prior LBS studies have primarily focused on the LBS revolution (Bellavista et al., 2008), geographical position techniques (GrejnerBrzezinska and Kealy, 2013), search behavior (Daurer et al., 2013), transmission techniques (Li and Longley, 2006; Li, 2006), LBS design and applications (Steinfield, 2004; Sultan and Rohm, 2008), users' perception of LBS (Junglas and Watson, 2008), choice of LBS (Constantiou et al., 2014), and privacy issues (Junglas et al., 2008; Xu et al., 2009; Zhou, 2013). However, the factors that determine continuance of newly developed SLBS remains unknown. It is interesting to note that SNS not only enhance the capabilities of LBS but also act to decrease users' concerns regarding LBS. While many users might be uncomfortable with the privacy issues associated with LBS, when they are integrated into an SNS platform users are more willing to provide access to this type of data in exchange for a service they find useful (Brustein, 2010). It's apparent that social network sites have changed the way people perceive and use LBS (Krishnamurthy and Pelechrinis, 2013). The transformation of SLBS and the attendant change in users' behavior is an obvious avenue of research, yet, empirical work in this area is rare (Krishnamurthy and Pelechrinis, 2013; Yu et al., 2013).

This research investigates the factors that influence users' satisfaction and the factors that contribute to a user's continued use of SLBS. Specifically, this paper intends to answer the following research questions.

\section{What performance attributes do users} expect from SLBS?

2. What post consumption expectations do SLBS users have?

3. What factors drive the satisfaction and continuance of SLBS users?

Using a theoretical framework derived from Expectation Confirmation Theory (Oliver, 1997; Bhattacherjee, 2001), this study considers the features of SLBS to empirically examine the performance, expectation, satisfaction, and continuance of SLBS. Our findings intend to provide 
insights relevant to mobile phone carriers, $\mathrm{m}$-commerce retailers, and social network services providers. A comprehensive understanding of users' expectations and needs are fundamental to both service providers and mobile device manufacturers during the design and roll-out processes of products and services. The insights provided from this research can better inform multiple actors within the personal mobile communications sector as they design and implement technologies, services, business models, and marketing strategies.

This paper is organized as follows. Section 2 reviews studies related to social locationbased services and introduces expectation confirmation theory. Section 3 proposes our theoretical model and explores the reasoning that founds our hypotheses. Section 4 contains a discussion of the instruments employed in the research, the demographics of the respondents, and scale validation. Section 5 examines the results and hypotheses testing. Section 5 is a discussion of our results and implications. Section 7 concludes with our findings, theoretical and practical contributions, limitations and suggestions for future research.

\section{Literature Review}

The following section reviews studies of SNS and LBS, and examines contemporary definitions of SLBS. Expectation Confirmation Theory, the theoretical basis for our research model, is reviewed in the latter half.

\section{Social Location-based Services}

Social network sites such as Facebook, MySpace, Twitter, and Foursquare have attracted hundreds of millions of users, many of whom have integrated these sites into their lifestyles. SNS are defined as webservices that allow users to construct a public profile within a bounded system, integrate a list of other users with whom they connect, and interact through these connections (Boyd and Ellison, 2007). Participatory SNS actions include sharing updated activities and positions, sharing photos and archiving events, getting updates on the activities of friends, communicating to, and following a large social network, sending messages privately, and posting public testimonials. LBS are defined as mobile services that extend the processing capability of spatial and temporal information to end users via the Internet and wireless communication technologies (Dhar and Varshney, 2011; Rao and Minakakis, 2003; Hazas et al., 2004). Combining the features of SNS and LBS, SLBS is defined as software applications that specifically exploit realtime spatial information in tandem with the communication channels of interconnected social networks. Users "check in" locations from their mobile devices in order to connect with friends, and access offers and relevant information from localized services specific to their online history or current online activities. SLBS allows users to share their location with friends and the public in a variety ways (Marks, 2012). It also enables vendors to target users and further provide location-based services and advertising (Dhar and Varshney, 2011).

Prior studies within the field of LBS have focused on its inherent challenges and opportunities ( $\mathrm{Li}, 2006$; Junglas and Watson, 2008; Suikkola, 2010; Dhar and Varshney, 2011). Previous studies have suggested that technological challenges, new business models, and privacy constitute the major issues regarding users' acceptance of LBS. However, SLBS have not yet been examined in detail. It remains unknown whether consumer attitudes toward the use of SLBS are similar or distinct from their approach to LBS. It is recognized that many people harbor privacy concerns regarding the implementation of LBS, yet when this technology is integrated into social network platforms and applications that provide access to relevant user-specific information, users are willing to temper their concerns. Many people express concern about privacy 
when sharing their location and personal information online, but SLBS users are willing to provide access to this type of data in exchange for a service they find useful (Brustein, 2010). Because SLBS have the potential to bridge to multiple social networks through one user, and have access to a rich trove of personal information, they present a potent field for corporate development. Since 1999, venture capitalists have invested $\$ 115$ million into location-centered start-up companies (Miller and Wortham, 2010). Mobile app stores have been flooded with SLBS that allow people to share their locations and favorite places with friends or find friends or places of interest near their current location (Wortham, 2012).

Users expect high return from integrating SLBS into their digital lives. The continuous stream of innovative applications means that users' behavior and their concerns change in concert with each new development. A real-time GPS coordinate might have been arresting to a user at the end of the last millennium, but today, amid a plethora of apps, developers that integrate SLBS into their communications must find appeal within a very savvy user community that has access to literally thousands of applications vying for consumers. Prior studies may not be able to fully explain contemporary SLBS user behavior. Therefore, this research attempts to address the following questions: What is the value offered by SLBS platforms? What are users' expectations of SLBS? What expectations should be considered to create SLBS user satisfaction? These questions are critical inquiries in the development of strategic measures undertaken to ensure a user's retention of SLBS. The Expectation Confirmation Model serves as the theoretical framework to explain the continuance of SLBS.

\section{Expectation Confirmation Theory}

The consumer satisfaction/dissatisfaction model (CS/D), an alias of the expectation confirmation/disconfirmation model (Van
Montfort et al., 2000; McKinney et al., 2002; Spreng and Chiou, 2002), has been widely used to explain what transpires between a user's initial acceptance to of a product and their decision to continue using it. CS/D postulates that user satisfaction (or dissatisfaction) is the most dominate antecedent that determines users' repurchase intention. User satisfaction (or dissatisfaction) in turn is a linear function proportional to confirmation (or disconfirmation) and pre-consumption expectations of users. In addition, a cognitive comparison between preconsumption expectations and actual experiences with that product or service leads to a subjective calculation of confirmation (or disconfirmation) (Oliver, 1980; Oliver et al., 1994). Thus, perceived performance is defined as individuals' perceptions of how a product or service's performance fulfills their needs, wants and desires. Some theorists argue that perceived performance has a direct effect on user satisfaction (Churchill and Suprenant, 1982; Tse and Wilton, 1988) and refer to this augmented model as the Expectance Confirmation with Performance Model (Oliver, 1997).

Bhattacherjee (2001) proposes a revised Expectation-Confirmation Theory (ECT) to address a user's continued use of an adopted information system. While CS/D examines both pre- and post-consumption variables, Bhattacherjee's (2001) ECT focuses only on post-acceptance variables and replaces pre-consumption expectations with post-consumption expectations. Cognitive dissonance theory proposed that confirmation/disconfirmation between preconsumption expectations and perceived performance could affect post-consumption expectations because rational individuals continually adjust their perceptions (e.g., expectation) so that the psychological tensions caused by confirmation/disconfirmation are reduced (Festinger, 1957). When confirmation/disconfirmation occurs, it is likely that post-consumption expectations 
will change (extend or shrink) to accommodate renewed perceptions. Thus, post-consumption expectations replace preconsumption expectations in consumers' cognitive memory as the basis for guiding subsequent behaviors (Bhattacherjee, 2001).

\section{Theoretical Model}

This research employs a theoretical model that captures the critical elements of perceived performance and postexpectations from the Expectation Confirmation Models of Oliver (1997) and Bhattacherjee (2001). Oliver's (1997) ECT model emphasized perceived performance and Bhattacherjee's (2001) emphasized post-expectation. Our proposed model combines these two models to specifically identify the factors that can measure perceived performance and post expectation in SLBS users. Four variables are used to measure the perceived performance of a SLBS: perceived usefulness, perceived enjoyment, interactivity, and privacy. The postexpectation of SLBS users measures needs such as information sharing and personalization. Figure 1 shows our proposed theoretical model.

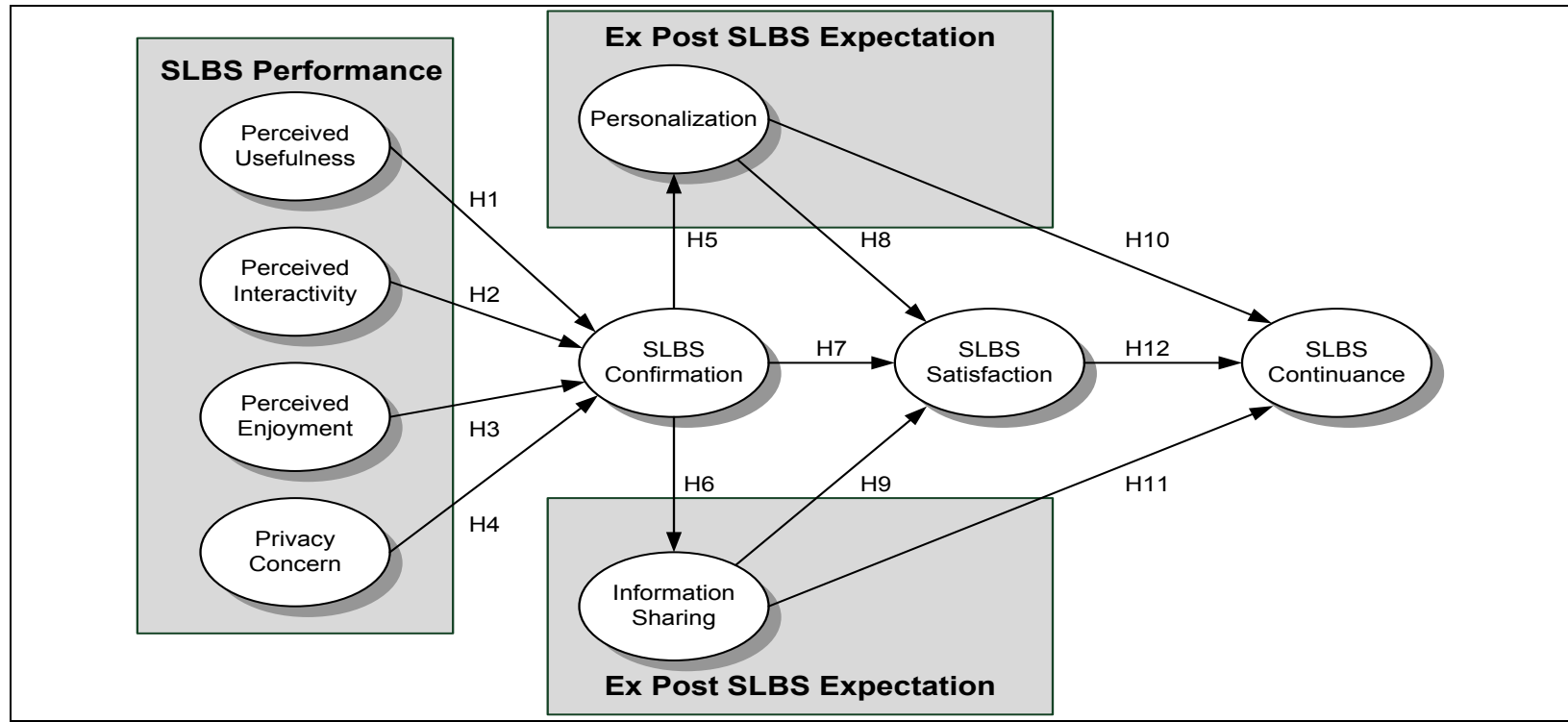

Figure 1 - Theoretical Model

\section{SLBS Performance to SLBS Confirmation}

Perceived performance is defined as individuals' perceptions of how a product or service performance fulfills their needs, wants, and desires (Cadotte et al., 1987). SLBS performance is defined as the users' perceptions of how well a SLBS fulfills their needs, wants, and desires when they use a SLBS. SLBS confirmation is defined as users' subjective judgments resulting from comparing their SLBS expectations and their perceptions of performance (Spreng et al., 1996). Users assess their perceived performance of SLBS based on a comparison of their initial beliefs and their real experiences and thereby determine the extent to which their expectations have been met. SLBS confirmation is defined as users' judgments resulting from comparing their SLBS expectation and their perceptions of performance. SLBS confirmation represents the comparisons 
between SLBS performance and expectations. SLBS performance is positively related to SLBS confirmation because it implies realization of the expected benefits of SLBS use.

To establish measures of SLBS performance, we have identified the salient elements of users' needs and concerns from prior studies. These salient elements include perceived usefulness, enjoyment, interactivity, and privacy concerns. These constitute four basic requirements of any SLBS. Perceived usefulness is a widely examined factor in measuring system performance (McKinney et al., 2002). Perceived usefulness is defined as the degree to which users believe that using a particular technology will enhance their performance (Davis, 1989). The higher the extent of perceived usefulness of using SLBS, the more likely it will be that users will confirm their use of SLBS. This leads to our first hypothesis.

\section{H1: The extent of perceived SLBS usefulness is positively related to users' confirmation of SLBS.}

Interactivity is considered an important factor for the measurement of performance (Eighmey and McCord, 1998; McKinney et al., 2002). Prior studies have defined perceived interactivity in different dimensions and from various perspectives (Steuer, 1992; Liu and Shrum, 2002; McMillan and Hwang, 2002; Jiang and Benbasat, 2007; Campbell et al., 2010; Animesh et al., 2011). Many of these studies have adopted Steuer's (1992) definition as a starting point: "the extent to which users can participate in modifying the form or content of a mediated environment in real time." McMillan and Hwang (2002) defined interactivity from four different perspectives: a feature of a technology, a process of message exchange, a users' perception after using a technology or going through a process, and the combination of the above three perspectives. From the users' perception perspective, perceived interactivity is defined as "the degree to which users perceive their experiences as a simulation of interpersonal interaction and sense they are in the presence of a social other" (Thorson and Rodgers, 2006). Most definitions emphasize the primacy of twoway communication and the participant's sense of control (Mollen and Wilson, 2010). In the SLBS context, we defined perceived interactivity as the extent to which a communication system can allow one or more participants to communicate alternatively as senders or receivers with one or many other users or communication devices (Fortin and Dholakia, 2005). We argue that the higher the degree of a SLBS user's perceived interactivity, the greater the extent of their confirmation to their use the SLBS. This argument leads to our second hypothesis.

\section{H2: The perceived interactivity of a SLBS is positively related to users' confirmation of SLBS.}

We use perceived usefulness and interactivity to capture the utilitarian elements of SLBS use. Since SLBS is a consumer-oriented service, we further argue that the hedonic dimension should also be considered. Perceived enjoyment is defined as the affective and sensory experience of aesthetic or sensual pleasure, fantasy, and fun (Hirschman and Holbrook, 1982). Information System (IS) researchers have treated perceived enjoyment as the degree to which using a technology is perceived to be enjoyable in its own right (Davis et al., 1992). We argue that the higher the degree SLBS users perceive enjoyment, the higher the degree of their confirmation of SLBS use. This argument leads to our third hypothesis.

H3: The perceived enjoyment of using a SLBS is positively related to users' confirmation of SLBS.

In addition to the positive elements of SLBS performance, we further consider privacy concerns which may negatively reflect SLBS performance. According to a report from Nielsen, many Americans hold strong privacy concerns regarding divulging 
personal information when using LBS (Bilton, 2011). Although some people still use LBS, many are reluctant to share information about their geographic location. SLBS users may receive unsolicited mobile advertising which is usually considered intrusive and users may feel these marketing efforts encroach upon their privacy (Dhar and Varshney, 2011). Privacy refers to an individual's ability to control when, how, and to what extent his or her personal information is made available (Dinev and Hart, 2006). In this study, we define privacy concerns as apprehensions related to the inability to control when, how, and to what extent personal information is made available. We argue that users' privacy concerns regarding SLBS are negatively related to SLBS confirmation.

\section{H4: The extent of SLBS privacy concerns is negatively related to users' confirmation of SLBS.}

Social media and mobile devices have changed consumers' behavior dramatically. Behavior researchers argue that some consumers are willing to disclose their personal information in exchange for some economic or social benefits (Laufer and Wolfe, 1997; Chellappa and Sin, 2005). Consumers engage in a privacy calculation where they trade privacy costs incurred by sharing information for the value obtained from personalization (Chellappa and Shivendu, 2007). To date, there have not been any empirical studies regarding the relationship between privacy concerns and users' confirmation of SLBS. Whether information disclosure endangers the privacy of SLBS users must be taken into account when considering SLBS performance. Thus, we include privacy concerns in measuring SLBS performance.

\section{SLBS Confirmation and Expectation}

Within the discourse regarding SLBS confirmation and expectation, SLBS confirmation refers to users' judgments that result from a comparison of their SLBS expectation and their perceived performance. Expectation is defined as a set of beliefs that are weighed by an evaluation of outcomes (Oliver, 1980). Expectation is measured as the ex post expectation because, a function of many products and especially mobile devices and services, is that their users' expectations may change over time (Bhattacherjee, 2001). We argue that personalization and information sharing are two critical elements that users expect from using SLBS. That is, users expect SLBS to have extensive interactivity and information sharing capabilities. First, personalization is an important post-consumption expectation of SLBS because users usually demand greater customization of content and services after they have gained sufficient knowledge and experience in SLBS usage. Users may have high initial personalization perceptions of SLBS because they expect to use the embedded position data to navigate within their real and digital environment and access the location of contacts in their social networks. Personalization has been considered the decisive feature of SLBS and offers significant value by placing information, transactions, and entertainment in a location-specific context (Bellavista et al., 2008; Ho, 2012).

Personalization is defined as the ability to provide content and services that are customized to consumers based on knowledge about their preferences and behaviors (Adomavicius and Tuzhilin, 2005). Personalization is the process of generating and presenting the right content in the right format to an individual at the right time in the right location (Ho, 2012). The value of personalization is that it emphasizes individualized functions that engender superior user experiences and enhance the ease of interaction (Zimmermann et al., 2005; Xu et al., 2009). We measure the post expectation of SLBS by using perceived personalization. Perceived personalization may be elevated as the result of confirmation experience, when users realize their initial perceptions were relatively low. If 
users' pre-acceptance personalization perceptions are disconfirmed during actual use, they may experience cognitive dissonance or psychological tension (Bhattacherjee, 2001). In recognition of the reality of use, rational users may try to rectify the dissonance by adjusting their initial perceptions. That is, SLBS confirmation will increase users' post use expectation, perceived personalization. Hence, we propose our fifth hypothesis:

H5: The extent of users' SLBS confirmation is positively related to their ex post SLBS expectation, perceived personalization, of SLBS use.

In addition to perceived interactivity, we further consider information sharing as another post expectation of SLBS use. Knowledge or information sharing plays a critical role in the development of social communities (Alavi and Leidner, 2001; Zhang et al., 2010; Chai et al., 2011). Trust, strength of social ties and reciprocity has positive effects on users' knowledge sharing behavior in SNS (Chai et al., 2011). Closer social ties result in more frequent and relevant information sharing between highly active partners. Information sharing is defined as the extent to which important information is communicated to one's partner (Mohr and Spekman, 1994). We measure post expectations of SLBS with information sharing because sharing information is the fundamental function of SLBS use. Users share their own information or communications to maintain relationships through SLBS. Information sharing is the primary purpose of SLBS adoption. Users share information in SLBS by "checking-in" at stores or revealing their current locations to friends or vendors. Although expectation is a broader construct within generalized consumer theory, perceived personalization is an adequate expectation measurement in the continuance of SLBS use because it isolates the significant beliefs that influence users' intentions across temporal stages of mobile device use.
The success of a new information technology is a function of how people use it (Constant et al., 1994). Friendships, personal contact with others, and commitment to the community are the primary drivers of information sharing among people (O'Reilly and Chatman, 1986; Kraut et al., 1990). SLBS helps users build valuable social networks through which they share information and their location. Users hold substantial expectations regarding the ability to share information when they use SLBS. Thus, we use information sharing to measure users' expectation because meeting this set of expectations has the ultimate bearing on a user's perception of the utility of SLBS. By sharing information, communicating thoughts and ideas, and being more familiar with the activities of their virtual community, SLBS users are able to actively pursue new contacts and maintain established relationships over time. Information sharing is a key post-adoption expectation for SLBS platforms because social network connections rely on the trust between the community members while information sharing is a key mechanism that establishes a solid bind between users and enhances mutual trust. In reference to the ECT model, we argue that the higher value that users confirm from using SLBS, the higher the users' expectation of information sharing. This leads to hypothesis 6 :

H6: The extent of SLBS users' confirmation is positively related to their ex post expectation, information sharing, of using SLBS.

\section{SLBS Satisfaction}

The measurement and strategic manipulation of consumer satisfaction is a fundamental tool used by marketing practitioners to enhance customer loyalty and increase market share and revenues. ECT argues that satisfaction is determined by the confirmation of a consumer's expectations of products and services that are met during actual use (Bhattacherjee, 2001). Satisfaction is met or unfulfilled as a result of a comparison between perceived 
service quality and consumers' prior expectations (Pantouvakis and Lymperopoulos, 2008; Wang, 2011). That is, when service quality meets expectations or surpasses expectations, satisfaction will be achieved. SLBS users achieve satisfaction based on their confirmation level and expectations upon which that confirmation was based. Confirmation is positively associated with satisfaction because it implies the realization of the expected benefits of IS use (Bhattacherjee, 2001; Bhattacherjee and Premkumar, 2004; Venkatesh and Goyal, 2010). Higher levels of SLBS confirmation will lead to higher levels of SLBS satisfaction.

In addition, users expect an extensive personalization capability in their SLBS. By altering the initial generic services they expect SLBS to reflect their specific personal needs in terms of searching for friends and accessing information relevant to their current physical and temporal position. Thus, SLBS that meet personalization expectations will garner higher consumer satisfaction levels. In concert with users' expectations of personalization, their expectations regarding information sharing are also intimately related to the satisfaction they derive from SLBS use. That is, SLBS that meets or exceeds expectations of information sharing will lead to higher satisfaction with SLBS use. Hence, our eighth and ninth hypotheses are as follows.

H7: The extent of user's SLBS confirmation is positively associated with their satisfaction with SLBS use.

H8: The extent of a user's personalization expectation is positively associated with their satisfaction with SLBS use.

H9: The extent of a user's information sharing expectation is positively associated with their satisfaction with SLBS use.

\section{SLBS Continuance}

According to ECT, post expectations and satisfaction lead to IS continuance (Bhattacherjee, 2001). In Bhattacherjee's (2001) ECT model perceived usefulness is employed to measure the post expectation of IS use. In the SLBS context, we propose that personalization and information sharing are the two critical post-consumption expectation factors that determine SLBS adoption. We argue that personalization and information sharing are the two salient functions that influence a consumer's continued use of SLBS. The impact of customer satisfaction on long-term corporate profitability and market value cannot be overestimated (Gruca and Rego, 2005). Satisfying or exceeding customers' expectations is fundamental to establishing and retaining a loyal base of long-term consumers (Bhattacherjee, 2001).

An understanding of users' intentions to continue using SLBS is derived from a critical examination of their satisfaction. Consumer satisfaction is defined as an overall evaluation based on the customer's total purchase and consumption experience with a product or service (Luo and Bhattacharya, 2006). Satisfaction affects future purchase intention as well as postpurchase attitude (Oliver, 1980). ECT holds that consumers' satisfaction with prior use of a service or product dominates their consequent intention to continue using that service or product (Oliver, 1980; Anderson and Sullivan, 1993; Oliver and Westbrook, 1993). This leads to our last three hypotheses:

H10: The extent of a user's personalization expectation is positively associated with their continuance with SLBS.

H11: The extent of a user's information sharing expectation is positively associated with their continuance with SLBS.

H12: A users' level of satisfaction with initial SLBS use is positively associated with their SLBS continuance. 
SLBS has significantly changed consumer behavior in many ways. Contemporary expectations of SLBS capabilities call for a new theoretical perspective to explain these changing behaviors. To apply our proposed Expectation Confirmation Model in the SLBS context, we include the pertinent features of SLBS in our model (See Figure 1). To capture users' critiques of SLBS features, we measure SLBS performance with four factors: perceived usefulness, perceived interactivity, perceived enjoyment, and privacy concerns. SLBS expectation is measured by personalization and information sharing. This ECT model captures the relevant factors that inhibit or enhance a consumer's esteem of SLBS performance, expectation, confirmation, satisfaction, and continuance.

\section{Research Method}

We conducted survey to collect empirical data and test all hypotheses proposed in this study. The instrumentation, sampling method, and scale validation of the survey are described below.

\section{Instrumentation}

The survey instrument is a two-part questionnaire. The first part uses nominal scales to collect basic information about the respondents. Items measuring respondent characteristics include gender, age, education, occupation, favorite brand of mobile phone, favorite telecom service provider, and frequency per week of SLBS usage. The second part uses subjective measures in the form of a 7-point Likert scale to evaluate respondents' perceptions of SLBS usage. The subjective measures are developed based on the measurement items in prior theories and studies. These items are further categorized into constructs in theory. All of the constructs in our research model are depicted as reflective latent constructs. All questionnaire items and sources are listed in Appendix I.
If the predictor and criterion variables are obtained from the same source, it is easy to induce common method biases. Thus, the techniques of counterbalancing question order and psychological separation of measurement are used to avoid common method biases (Podsakoff et al., 2003). Two batches of questionnaires with counterbalancing order were designed. Each construct is re-specified by a cover story page that keeps the measurement from being connected with other constructs and creates a psychological separation. Pretests of the questionnaire are performed in two steps to eliminate possible weakness and flaws in the questionnaire design. The first pretest was performed with 40 students to refine the questionnaire items. We further conducted a second pretest with an expert panel to confirm the final version and revise the wording and terminology.

\section{Sample Organizations and Respondents}

The subjects are users with extensive experience with SLBS platforms via their mobile devices such as smartphones, PDAs, iPads, etc. To collect empirical data, we posted our online survey in major mobile phone online forums and mobile services online discussion board. Excluding invalid responses, a total of 464 valid samples were obtained. Table 1 summarizes the demographics of respondents.

We adopted Armstrong and Overton's (1977) methods to test non-response bias. The online survey was posted as a highlighted announcement on top of the forum to ensure that every user entering the forum could see the questionnaire. The characteristics of the late respondents are very similar to that of non-respondents. To account for this type of respondent we included a binomial quiz item in the questionnaire to ask whether the visitor was a first-time respondent. Only the first-time respondents were accepted as valid respondents. Based on Armstrong and Overton's (1977) suggested approach, the respondent samples were further divided 
into early $(75 \%)$ and late $(25 \%)$ groups according to the time-log of the respondents that completed the questionnaire. These two groups were further compared using $x^{2}$ tests in terms of their demographic characteristics. The results demonstrated the characteristics of these two groups were statistically similar.

We also used a follow-up method to check non-response bias. We posted another survey with ten questions contained in the original questionnaire after the first round survey. The questionnaire also included a binomial quiz item to check whether a respondent had replied to the first-round survey. Only non-respondents who did not reply to the first-round survey were invited to complete the questionnaire and chosen as valid non-respondents. The nonrespondents were validated by examining their answer to the binomial question. The $T$ tests indicated no significant mean differences between the respondent and non-respondent samples on these questions.

\begin{tabular}{|c|c|c|c|c|c|}
\hline Characteristics & Number & $\%$ & Characteristics & Number & $\%$ \\
\hline \multicolumn{3}{|l|}{ Gender: } & \multicolumn{3}{|l|}{ Mobile phone brands: } \\
\hline Male & 237 & 51.08 & HTC & 160 & 34.48 \\
\hline Female & 227 & 48.92 & iPhone & 90 & 19.40 \\
\hline \multicolumn{3}{|l|}{ Age: } & LG & 20 & 4.31 \\
\hline$<19$ & 23 & 4.96 & Motorola & 14 & 3.02 \\
\hline $19-22$ & 118 & 25.43 & Nokia & 50 & 10.78 \\
\hline $23-25$ & 174 & 37.50 & SAMSUNG & 48 & 10.34 \\
\hline $26-30$ & 95 & 20.47 & Sony Ericsson & 77 & 16.59 \\
\hline $31-40$ & 41 & 8.84 & Other & 5 & 1.08 \\
\hline$>40$ & 13 & 2.80 & & & \\
\hline \multicolumn{3}{|l|}{ Education: } & \multicolumn{3}{|c|}{ Telecom service providers: } \\
\hline Junior High school & 2 & 0.43 & Taiwan Mobile & 115 & 24.78 \\
\hline High school & 33 & 7.11 & Chunghwa Telecom & 237 & 51.08 \\
\hline Junior College & 14 & 3.02 & Far Eastone Telecom & 84 & 18.10 \\
\hline College & 290 & 62.50 & Vibo Telecom & 9 & 1.94 \\
\hline Graduate college & 122 & 26.29 & Asia Pacific Telecom & 19 & 4.10 \\
\hline Ph.D. & 3 & 0.65 & & & \\
\hline \multicolumn{3}{|l|}{ Occupation: } & \multicolumn{3}{|c|}{ Frequency of SLBS use per week: } \\
\hline Student & 220 & 47.41 & 0 & 38 & 8.19 \\
\hline Information & 33 & 7.11 & $1-2$ & 125 & 26.94 \\
\hline Business & 13 & 2.80 & $3-4$ & 106 & 22.84 \\
\hline Military and Government & 47 & 10.13 & $5-6$ & 63 & 13.58 \\
\hline Services & 71 & 15.30 & $7-8$ & 36 & 7.76 \\
\hline Manufacturing & 18 & 3.88 & $>8$ & 96 & 20.69 \\
\hline Finance and Insurance & 10 & 2.16 & & & \\
\hline Other & 52 & 11.21 & & & \\
\hline
\end{tabular}




\section{Scale Validation}

To evaluate the psychometric properties of the instrument, we adopt the covariancebased structural equation modeling (SEM) method to perform confirmatory factor analysis (CFA) with AMOS 20. The measurement model is built to assess convergent and discriminant validity of latent constructs. Each latent construct is modeled as a reflective construct accounting for its indicators. All latent constructs are designed to correlate with each other. Model estimation is executed through use of the maximum likelihood technique. The measurement model demonstrates goodness of fit for the empirical data and meets the requirements of specific overall fit indices.

For example, chi-square normalized by degrees of freedom (x2/df) should be lower than five; adjusted goodness-of-fit index (AGFI) should be greater then 0.8 , goodness-of-fit index (GFI), normed fit index (NFI), and comparative fit index (CFI) should all exceed 0.9 , and root mean square error of approximation (RMSEA) should be lower than 0.05 to indicate good approximate fit (Hair et al., 1998; Segars, 1997). Convergent validity was assessed by three criteria: (1) all item loadings $(\lambda)$ should be statistically significant and exceed 0.70 and, (2) composite reliability for each construct should exceed 0.70 , and (3) average variance extracted (AVE) for each construct should be larger than 0.50 . Next, discriminant validity between constructs was assessed using the criterion that the square root of AVE for each construct should exceed the correlations between that and all other constructs (Fornell and Larcker, 1981; Chin, 1998; Hair et al., 1998)

In the current measurement model, the overall fit indices $(X 2 / d f=762.76 / 695=1.10$, $A G F I=0.91, \mathrm{GFI}=0.92, \mathrm{NFI}=0.95, \mathrm{CFI}=0.99$, RMSEA $=0.015$ ) confirmed an adequate model fit for the empirical data. Furthermore, all constructs have also shown good convergent validity as all of the criteria for convergence were met. As shown in Table 2 , standardized item loadings ranged from 0.73 to 0.94 . All item loadings exceeded the minimum loading criterion of 0.71 and were significant at the $p<0.001$ level. Composite reliability ranged from 0.88 to 0.93 , average variance extracted (AVE) ranged from 0.65 to 0.78 . Composite reliabilities of all factors exceeded the minimum requirement of 0.70 , and all AVE values were greater than the recognized 0.50 cut-off. The results indicate that all first-order constructs have a high degree of reliability and convergent validities. The square root of AVE for each construct exceeded its correlations with all other constructs (See Table 3). Thus, all constructs met the criterion for discriminant validity. Appendix II shows the variancecovariance matrix of all items.

We adopted the single-specific-methodfactor approach with social desirability as latent method factor to identify the common method bias (Podsakoff et al., 2003). The chi-square difference test was performed to compare the measurement model and the single-specific-method-factor model because these two models were nested. The overall fit indices $(X 2 / d f=762.55 / 668=1.14, \quad \quad A G F I=0.91$, $\mathrm{GFI}=0.92, \mathrm{NFI}=0.95, \mathrm{CFI}=0.99$, RMSEA = 0.017 ) shown the single-specific-methodfactor model had an adequate model fit for the empirical data. The difference between the chi-square for the two models was 0.21 (762.76-762.55=0.21) and the difference between the degrees of freedom for the two models was $27 \quad(695-668=27)$. The chisquare difference between the two models was insignificant indicating the singlespecific-method-factor mode didn't significantly reduce model fit. Thus, the common method bias was insignificant in our survey study. 


\begin{tabular}{|c|c|c|c|c|c|c|c|}
\hline Constructs & Items & Means & $\begin{array}{l}\text { Std. } \\
\text { Dev. }\end{array}$ & $\begin{array}{l}\text { Std. } \\
\text { Loadings }\end{array}$ & $\begin{array}{l}\mathrm{T} \\
\text { Statistics }\end{array}$ & AVE & \begin{tabular}{|l} 
Composite \\
Reliability
\end{tabular} \\
\hline \multirow{4}{*}{$\begin{array}{l}\text { Perceived } \\
\text { Usefulness }\end{array}$} & PU1 & 5.23 & 1.13 & 0.88 & 23.92 & \multirow{4}{*}{0.78} & \multirow{4}{*}{0.93} \\
\hline & PU2 & 5.35 & 1.10 & 0.94 & 26.37 & & \\
\hline & PU3 & 5.26 & 1.12 & 0.89 & 24.22 & & \\
\hline & PU4 & 5.55 & 1.02 & 0.82 & 21.17 & & \\
\hline \multirow{4}{*}{$\begin{array}{l}\text { Perceived } \\
\text { Enjoyment }\end{array}$} & PE1 & 5.19 & 1.04 & 0.86 & 22.58 & \multirow{4}{*}{0.76} & \multirow{4}{*}{0.93} \\
\hline & PE2 & 5.18 & 1.03 & 0.87 & 23.19 & & \\
\hline & PE3 & 5.31 & 1.10 & 0.89 & 24.08 & & \\
\hline & PE4 & 5.27 & 1.13 & 0.80 & 20.49 & & \\
\hline \multirow{4}{*}{$\begin{array}{l}\text { Perceived } \\
\text { Interactivity }\end{array}$} & IA1 & 5.22 & 1.07 & 0.83 & 21.35 & \multirow{4}{*}{0.74} & \multirow{4}{*}{0.92} \\
\hline & IA2 & 5.16 & 1.04 & 0.82 & 20.71 & & \\
\hline & IA3 & 5.44 & 1.09 & 0.82 & 20.99 & & \\
\hline & IA4 & 5.30 & 1.13 & 0.83 & 21.25 & & \\
\hline \multirow{4}{*}{\begin{tabular}{|l} 
Privacy \\
Concern
\end{tabular}} & PV1 & 5.74 & 1.12 & 0.88 & 23.86 & \multirow{4}{*}{0.78} & \multirow{4}{*}{0.93} \\
\hline & PV2 & 5.78 & 1.11 & 0.88 & 23.90 & & \\
\hline & PV3 & 5.73 & 1.17 & 0.90 & 24.66 & & \\
\hline & PV4 & 5.76 & 1.15 & 0.87 & 23.17 & & \\
\hline \multirow{4}{*}{ Personalization } & PS1 & 5.16 & 1.08 & 0.81 & 20.38 & \multirow{4}{*}{0.69} & \multirow{4}{*}{0.90} \\
\hline & PS2 & 5.27 & 1.03 & 0.89 & 23.16 & & \\
\hline & PS3 & 5.56 & 0.95 & 0.75 & 18.19 & & \\
\hline & PS4 & 5.04 & 1.12 & 0.75 & 18.11 & & \\
\hline \multirow{4}{*}{$\begin{array}{l}\text { Information } \\
\text { Sharing }\end{array}$} & IS1 & 5.45 & 1.12 & 0.87 & 23.00 & \multirow{4}{*}{0.74} & \multirow{4}{*}{0.92} \\
\hline & IS2 & 5.47 & 1.07 & 0.89 & 24.22 & & \\
\hline & IS3 & 5.44 & 1.09 & 0.89 & 23.85 & & \\
\hline & IS4 & 5.48 & 1.15 & 0.85 & 22.27 & & \\
\hline \multirow{4}{*}{ Confirmation } & SLBSC1 & 4.96 & 1.11 & 0.91 & 24.98 & \multirow{4}{*}{0.73} & \multirow{4}{*}{0.91} \\
\hline & SLBSC2 & 4.94 & 1.15 & 0.93 & 26.11 & & \\
\hline & SLBSC3 & 4.57 & 1.21 & 0.80 & 20.54 & & \\
\hline & SLBSC4 & 5.07 & 1.02 & 0.81 & 20.91 & & \\
\hline \multirow{4}{*}{ Satisfaction } & SF1 & 5.15 & 1.04 & 0.87 & 23.51 & \multirow{4}{*}{0.70} & \multirow{4}{*}{0.90} \\
\hline & SF2 & 5.21 & 1.04 & 0.89 & 24.28 & & \\
\hline & SF3 & 5.08 & 1.12 & 0.90 & 24.52 & & \\
\hline & SF4 & 5.14 & 1.07 & 0.88 & 23.95 & & \\
\hline \multirow{4}{*}{$\begin{array}{l}\text { Continuance } \\
\text { Intention }\end{array}$} & $\mathrm{Cl} 1$ & 5.37 & 1.08 & 0.92 & 25.65 & & \\
\hline & $\mathrm{Cl} 2$ & 5.33 & 1.11 & 0.94 & 26.84 & 73 & \\
\hline & $\mathrm{Cl} 3$ & 5.19 & 1.19 & 0.88 & 24.09 & 0.13 & 0.91 \\
\hline & $\mathrm{Cl} 4$ & 5.36 & 1.05 & 0.85 & 22.73 & & \\
\hline & SD1 & 5.38 & 0.97 & 0.79 & 19.00 & & \\
\hline Social & SD2 & 5.27 & 1.02 & 0.80 & 19.20 & 065 & \\
\hline Desirability & SD3 & 5.06 & 1.14 & 0.77 & 18.37 & 0.65 & 0.88 \\
\hline & SD4 & 5.16 & 1.11 & 0.73 & 17.06 & & \\
\hline
\end{tabular}




\begin{tabular}{|c|c|c|c|c|c|c|c|c|c|c|}
\hline Constructs & PU & PE & IA & PV & PS & IS & SLBSC & SF & $\mathrm{Cl}$ & SD \\
\hline PU & 0.88 & & & & & & & & & \\
\hline $\mathrm{PE}$ & 0.53 & 0.87 & & & & & & & & \\
\hline IA & 0.55 & 0.63 & 0.86 & & & & & & & \\
\hline PV & 0.22 & 0.15 & 0.18 & 0.88 & & & & & & \\
\hline PS & 0.43 & 0.37 & 0.45 & 0.24 & 0.83 & & & & & \\
\hline IS & 0.19 & 0.27 & 0.30 & 0.05 & 0.18 & 0.86 & & & & \\
\hline SLBSC & 0.54 & 0.55 & 0.57 & 0.14 & 0.36 & 0.27 & 0.85 & & & \\
\hline SF & 0.52 & 0.65 & 0.54 & 0.10 & 0.41 & 0.41 & 0.67 & 0.84 & & \\
\hline $\mathbf{C l}$ & 0.50 & 0.52 & 0.48 & 0.15 & 0.32 & 0.41 & 0.45 & 0.73 & 0.85 & \\
\hline SD & 0.07 & 0.07 & 0.11 & 0.04 & 0.09 & 0.23 & 0.06 & 0.03 & 0.04 & 0.81 \\
\hline
\end{tabular}

The diagonal values are the square root of the AVE for each construct.

PU: Perceived Usefulness, PE: Perceived Enjoyment, IA: Interactivity, PV: Privacy, PS: Personalization

IS: Information Sharing

SLBSC: Social Location-Based Service Confirmation, SF: Satisfaction, Cl: Continuance Intention, SD:

Social Desirability

\section{Results}

The structural model is used to estimate the path coefficients and explain variances within the research model. Model estimation is executed through use of the maximum likelihood technique. The evaluation of the structural model is carried out in four steps. First, the structural model has goodness of fit to the empirical data while the same fit indexes applied in assessing measurement model are met. Second, the standardized path coefficient and its statistical significance for each cause-effect relationship in the structure model are examined. Third, the squared multiple correlation for each endogenous construct is calculated to assess the predictive power of the structural model. The squared multiple correlations obtained from SEM analyses are similar to those R-square coefficients found in multiple regression analyses. Finally, the relative importance of each antecedent construct in affecting dependent latent variables is assessed in terms of its item loading.

For the hypothetic structural model, all fit indexes have suggested adequate model fit between the research model and the empirical data $(X 2 / \mathrm{df}=811.54 / 576=1.41$, $\mathrm{AGFI}=0.90, \mathrm{GFI}=0.91, \mathrm{NFI}=0.95, \mathrm{CFI}=$ 0.98, RMSEA $=0.030$ ). Figure 2 represents the results of hypotheses testing of our research model. Overall, the major findings are as follows. First, the results indicate that SLBS satisfaction and information sharing have significant path coefficients with value of 0.67 and 0.14 to SLBS continuance whereas personalization has no effect on SLBS continuance. SLBS satisfaction and information sharing jointly explains $55 \%$ of the variance in SLBS continuance. This result confirms that user satisfaction is a dominant antecedent of continuance intention. Thus, hypothesis 11 and 12 are supported whereas hypothesis 11 is unsupported.

Second, SLBS confirmation, information sharing, and personalization have significant effects on SLBS satisfaction. These three constructs obtain significant path coefficients with values of $0.57,0.22$, and 0.16 respectively and jointly explain about $55 \%$ of the variance in SLBS satisfaction. The SLBS confirmation is the major precursor of SLBS satisfaction whereas information sharing and personalization have weaker effects. This result confirms the suggestions of prior studies which argued expectationconfirmation is the main factor affecting user satisfaction. However, the ex-post expectations, i.e. information sharing and personalization, still have additional effects 


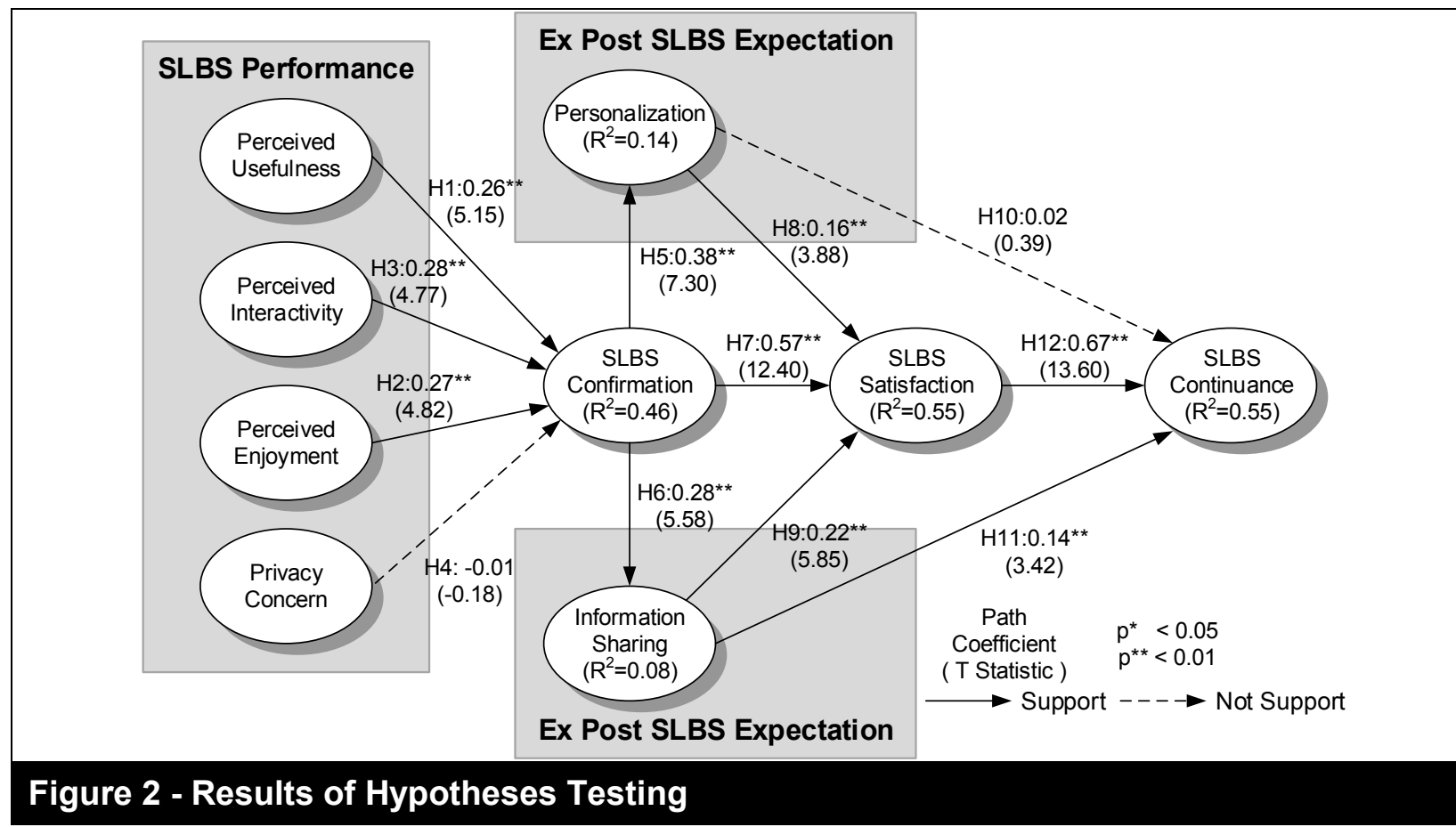

Third, SLBS confirmation is a salient antecedent of personalization and information sharing. SLBS confirmation has significant effects on personalization and information sharing with values of 0.38 and 0.28 respectively though it only explains $14 \%$ of the variance in personalization and $8 \%$ of the variance in information sharing. This result proves that confirmation will change the ex-post expectations of users. Thus, hypothesis 5 and hypothesis 6 are fully supported. However, the needs of personalization and information sharing are not derived primarily from SLBS confirmation. Some unidentified variables may exist that serve as motivators of personalization and information sharing.

Last, interactivity, perceived enjoyment, and perceived usefulness have significant effects with values of $0.28,0.27$, and 0.26 on SLBS confirmation respectively whereas privacy concerns are insignificant. The former three constructs jointly explain $46 \%$ of the variance in SLBS confirmation. Notice that the path coefficients of these three constructs show no great difference. They are all import antecedents of SLBS confirmation. This result reveals that interactivity, perceived enjoyment and perceived usefulness are the fundamental requirements for supporting SLBS usage. In other words, SLBS performance serves as the groundwork for confirming users' exante expectations of SLBS. Thus, hypotheses 1 to 3 are supported whereas hypothesis 4 is unsupported.

\section{Discussion}

These research findings provide implications for both scholars and practitioners engaged in verifying user expectations, managing SLBS design, satisfying customers, and understanding the continuance of SLBS. The following sections will comprise a detailed discussion these insights. 


\section{The Expected Performance of SLBS}

Answers to our first research question, regarding users' expectations of SLBS performance can be summarized as follows. Perceived usefulness, perceived enjoyment, and interactivity are three expected performance attributes of SLBS platforms. Successfully providing these performance functions may boost SLBS confirmation, SLBS satisfaction, and finally increase customer loyalty for a specific SLBS. Prior studies primarily measured IS performance in work environments which may not be appropriate for the SLBS context. Our results provide researchers with a new approach to measure consumer-centric task performance. The factors, isolated in this study, that measured consumer centric task performance, have rarely been discussed in previous studies.

Our results show that SLBS performance is the prerequisite that ensures users' actual experiences meet their ex-ante expectations of SLBS adoption. SLBS performance requires suitable integration of mobile devices and services and generally reflects both the utilitarian and hedonic desires of users. Mobile devices are usually excellent carriers for delivering personalized SLBS from service provides to users. Regardless of the service level the SLBS providers furnish, it is the capabilities of the mobile device that will affect users' perceptions of actual service quality. Well-designed mobile devices can deliver services without a reduction in quality and even increase the consumer's valuation of SLBS. It is easy for users to perceive that their actual experiences align with their expectations when SLBS performs well in terms of perceived usefulness, perceived enjoyment, and interactivity. These results are consistent with the findings of prior studies which argue that better interaction and information transactions between users and mobile devices will satisfy users' expectations more effectively (Li, 2006; Li and Longley, 2006). Thus, superior SLBS performance is a critical prerequisite for SLBS confirmation.
However, privacy concerns are found to not have a significant effect on SLBS confirmation. In comparison with the other three factors, privacy concerns only obtain an insignificant path coefficient with a value of -0.01 to SLBS confirmation. This result differs from the arguments of prior studies in which privacy concerns are one of the major issues affecting the adoption of LBS. We interviewed a number of respondents to explore the reasons why privacy concerns are not a significant antecedent of SLBS confirmation. Respondents indicate that they care more about the utility of SLBS and tend to neglect the loss of privacy. The trade-off of using SLBS is to ignore privacy concerns in order to increase social interactions, access personalized services, and the convenience of using SLBS.

These arguments are consistent with our findings in which perceived usefulness, perceived enjoyment, and interactivity are three significant functions of SLBS whereas privacy concerns are insignificant. This result shows that SLBS present a trade-off between privacy concerns and the advantages offered by SLBS. A prior study by Malhotra et al. (2004) provides a possible explanation for this phenomenon. They argued that the type of information (less sensitive or more sensitive) has a positive effect on risk beliefs and a negative effect on trust beliefs. Users are more comfortable sharing information when the requested information is less sensitive. Our respondents tend to believe that the information shared in SLBS is less sensitive and therefore poses a relatively low risk of exploitation. This may explain why privacy is not a significant concern in a SLBS context.

\section{The Ex-Post Expectations of SLBS}

Insights gained from our second research question, what are users' post expectations of a SLBS, can be summarized as follows. Personalization has been identified as the second most important ex-post SLBS expectation after SLBS confirmation. Personalization should be a critical strategic focus for service providers. Consumers 
expect a substantially customized user experience. This result confirms the findings of prior studies. In general business research, the ability to personalize products and services based on knowledge about customer preferences has long been considered as an important ability of firms (Adomavicius and Tuzhilin, 2005; Sheng et al., 2008). Although the advance of mobile devices has increased the diversity and richness of LBS (Bellavista et al., 2008), the design of LBS must be continually enhanced to meet users' ever changing needs as they change in tandem with the advances in LBS technology ( $\mathrm{Li}$ and Longley, 2006). Personalization will reshape SLBS designs and create new business models for SLBS providers. Both the utilitarian and hedonic desires of users create opportunities and challenges for service providers to invent new customized services. To remain viable, service providers must continuously enhance the personalization ability of platforms and device interfaces. Researchers should also examine the effect of personalization on user satisfaction and SLBS continuance in future research.

However, merely paying attention on the functionalities of SLBS is no longer sufficient to succeed in the competitive mobile commerce market. LBS applications have been integrated into various domains, especially that of SNS (Sultan and Rohm, 2008). SLBS have become an important sharing mechanism for virtual social communities (Zhang et al., 2010). The demand of information sharing with community members through SNS is increasing. As our research results have indicated, when users' actual experiences meet their ex-ante expectations of SLBS use, this SLBS confirmation will generate new ex-post expectations of information sharing. This means people will increasingly use SNS to interact with community members, post messages, and share location-based information. Though personalization and customization may enhance the flexibility of SLBS and more closely align its functionalities with the needs of users, information sharing is the most important ex-post user expectation in maintaining social network connections (Mohr and Spekman, 1994). Thus, in addition to the functionalities of SLBS, theorists and service providers should focus on information sharing capabilities.

Fueled by the advance of mobile devices, the popularity of SNS has attracted hundreds of millions of consumers that share information and maintain social connections with virtual community members. SLBS will generate significant network externality and substantially increase perceived value. The more users that register on SNS sites, the more the perceived value of SLBS will be increased. Information sharing needs and expectations will also increase. Thus, providing quality SLBS functionalities that satisfy users' needs should undoubtedly be the main concern of service providers. Researchers that intend to explore SLBS users' behavior should take these two dimensions into consideration.

\section{The Satisfaction and Continuance of SLBS}

Answers to our last research question, the factors that drive the satisfaction and continuance of SLBS, can be summarized as follows. First, SLBS satisfaction is confirmed as a critical factor that determines the continuing use of SLBS while the expost expectations, e.g. information sharing, may or may not contribute their auxiliary effects to continuance. SLBS satisfaction is mainly influenced by SLBS confirmation $(\beta=0.57)$ and subordinately affected by information sharing $(\beta=0.22)$ and personalization $(\beta=0.16)$. Thus, confirmation is the prerequisite for user satisfaction while the ex-post expectations are additional antecedents of user satisfaction. Second, the fulfillment of confirmation will generate new ex-post user expectations. For instance, personalization and information sharing are two specific ex-post expectations derived from the fulfillment of SLBS confirmation. 
In this study, SLBS confirmation refers to users' cognitive comparisons between exante expectations and actual experiences of SLBS usage. This means that users' exante expectations should be the fundamental requirement of SLBS functionalities and their delivery must be stringently considered by the service providers to ensure a good user perceived performance. The advance of SLBS offers more differentiated and customized applications will attract greater attention from users (Junglas and Watson, 2008). Advances in wireless networks and communication technology also facilitate the strengthening of intra-group ties and extends extra-group network range (Suh et al., 2011). Thus, SLBS confirmation will enhance users' dependence on SLBS and further expand their ex-post expectations (e.g., personalization and information sharing). Services providers may discover new business opportunities from mobile device and SLBS innovation.

\section{Conclusion}

SLBSs have generated profound interest because of their potential to provide a variety of personalized and context-aware services. The popularity of social network websites has also accelerated the acceptance of SLBS. Prior studies have suggested that technology breakthroughs, services availability, new business models, and privacy issues affect the acceptance of SLBS. These challenges were the motivation behind this research and led us to propose a theoretical framework that considers the features of SLBS. This research gives a detailed explanation of the factors that influence users' expectationconfirmation, satisfaction, and continuance of SLBS. Based on the ECT work of Oliver (1997) and Bhattacherjee (2001), we developed a modified ECT model specific to an exploration of SLBS usage behavior. This model can also be used as a vehicle to inform an understanding of other consumercentric technology usage. In this paper,
SLBS includes geo-positioning technology as well the ability to integrate social network service related features such as the sharing of information, providing checked-in locations through communications with friends, and providing highly personalized services. In light of the unique features and innovative integration of functions in contemporary SLBS platforms the model adopted for this research better explains the factors that affect users' perceptions of SLBS performance, confirmation, ex-post expectations, satisfaction, and continuance of use.

We conducted a survey to obtain data and empirically test our proposed model. Overall, we found that SLBS confirmation is critical to explain user satisfaction and continuance of SLBS. Our findings can be summarized as follows. First, SLBS performance (i.e. perceived usefulness, perceived enjoyment, and interactivity) serves as a prerequisite of users' SLBS confirmation. Higher SLBS performance will lead to higher SLBS confirmation. SLBS performance represents the integration of mobile devices and services that confirms users' SLBS ex-ante expectations. Second, the higher users' SLBS confirmation leads to higher SLBS ex post expectation, perceived personalization and information sharing. Third, higher confirmation of SLBS will lead to higher users' satisfaction with SLBS. Forth, ex post expectations, perceived personalization and information sharing capabilities, will also positively affect user satisfaction. Last, SLBS user satisfaction will lead to higher intentions to continuance use of SLBS.

The theoretical and practical contributions of this research are discussed below. First, drawing on expectation confirmation theory (ECT), we developed a dedicated theoretical framework to critique SLBS features in terms of user satisfaction and continuance use. We are not aware of other work that empirically analyzes the specific factors that encourage or discourage the adoption and retention of a SLBS platform. This study provides a more comprehensive evaluation of ECT in the consumer-centric 
technology and service context. Second, this paper is one of the first studies to examine user satisfaction and continuance use of SLBS. Prior studies have primarily focused on technological improvement (Hirsch et al., 2006; Jiang and Yao, 2006), LBS services design (Li and Longley, 2006) and privacy issues (Junglas et al., 2008) and have not adequately examined contemporary SLBS users' experiences and expectations. An appreciation of contemporary users' experiences and the manner in which they manipulate data and transform their chosen platform is of critical import for marketers and practitioners. The requirements and expectations of these users can pave the way for innovative designs. Third, our findings provide practical insights for mobile device developers so that they can improve their products by aligning the design with the functional expectations of SLBS users. Fourth, our findings also provide practical insights and potential avenues for marketing strategies for SLBS application developers in terms of conceiving new business models and increasing the use of SLBS.

The limitations of this paper followed by future research directions are addressed in the following. First, our findings may not be able to explain non-SLBS users' behaviors because our research focuses specifically on the factors that influence SLBS users satisfaction. For example, while privacy concerns may not be an issue for current SLBS users they may impede the acceptance of SLBS platforms within the non-user population. Future research can further investigate non-users' perceptions. Second, we only examine users in Taiwan; thus, the results may be limited to an explanation of SLBS user behaviors in the context of Asia countries. SLBS users in different countries and cultures might possibly desire distinct features and capabilities in SLBS platforms. Future research might consider a comparison between the SLBS perceptions of different countries and cultures.

\section{Acknowledgement}

The authors thank the Ministry of Science and Technology in Taiwan for partial support for this research under grant number NSC100-2410-H-017-017-MY2. We also thank $\mathrm{Dr}$. Angsana A. Techatassanasoontorn for her comments in the early version of this paper. We appreciate the anonymous reviewers who offered many useful suggestions and comments.

\section{References}

Adomavicius, G. and Tuzhilin, A. (2005). "Personalization Technologies: A Process-oriented Perspective," Communications of the ACM, 48(10), pp.83-90.

Alavi, M. and Leidner, D.E. (2001). "Review: Knowledge Management and Knowledge Management Systems: Conceptual Foundations and Research Issues," MIS Quarterly, 25(1), pp.107-136.

Armstrong, J.S. and Overton, T.S. (1977). "Estimating Nonresponse Bias in Mail Surveys," Journal of Marketing Research, 14 (3), pp.396-402.

Anderson, E.W. and Sullivan, M.W. (1993). "The Antecedents and Consequences of Customer Satisfaction for Firms," Marketing Science, 12(2), pp.125-143.

Animesh, A., Pinsonneault, A., Yang, S.B. and Oh, W. (2011). "An Odyssey into Virtual Worlds: Exploring the Impacts of Technological and Spatial Environment on Intention to Purchase Virtual Products," MIS Quarterly, 35(3), pp.20-27.

Bellavista, P., Kupper, A. and Helal, S. (2008). "Location-based Services: Back to the Future," IEEE Computer Society, 7(2), pp.85-89. 
Bhattacherjee, A. (2001). "Understanding Information Systems Continuance: An Expectation-confirmation Model," MIS Quarterly, 25(3), pp.353-370.

Bhattacherjee, A. and Premkumar, G. (2004). "Understanding Changes in Belief and Attitude Toward Information Technology Usage: A Theoretical Model and Longitudinal Model and Longitudinal Test," MIS Quarterly, 28(2), pp.229-254.

Bilton, N. (2011). "Location Apps Generate Privacy Concerns, Report Says," Retrieved from http://bits.blogs.nytimes.com/2011/04 21/location-apps-generate-privacyconcerns-report-says/ on August 21, 2014.

Bock, G.-W., Zmud, R.W., Kim, Y.-G. and Lee, J.-N. (2005). "Behavior Intention Formation in Knowledge Sharing: Examining the Roles of Extrinsic Motivators, Social-psychological Forces, and Organization Climate," MIS Quarterly, 29(1), pp.87-111.

Boyd, D.M. and Ellison, N.B. (2007). "SNS: Definition, History, and Scholarship," Journal of Computer-Mediated Communication, 13(1), pp.210-230.

Brustein, J. (2010). "Keeping a Closer Eye on Employees' Social Networking," Retrieved from http://bits.blogs.nytimes.com/2010/03 26/keeping-a-closer-eye-on-workerssocial-

networking/? php=true\& type=blogs \&module=Search\&mabReward=relbi as\%3As\& $r=0$ on September 10, 2014.

Cadotte, E.R., Woodruff, R.B. and Jenkins, R.L. (1987). "Expectations and Norms in Models of Consumer Satisfaction," Journal of Marketing Research, 24(3), pp.305-314.

Chai, S., Das, S. and Rao, H. (2011). "Factors Affecting Bloggers' Knowledge Sharing: An Investigation across Gender," Journal of Management Information Systems, 28(3), pp.309-342.

Campbell, D.E., Wright, R.T. and Clay, P.F. (2010). "Deconstructing and Operationalizing Interactivity: An Online Advertising Perspective," Journal of Information Technology Theory and Application, 11(4), pp.2953.

Chellappa, R.K. and Shivendu, S. (2007). "An Economic Model of Privacy: A Property Rights Approach to Regulatory Choices for Online Personalization," Journal of Management Information Systems, 24(3), pp.193-225.

Chellappa, R.K. and Sin, R. (2005). "Personalization versus Privacy: An Empirical Examination of the Online Consumer's Dilemma," Information Technology and management, 6(2-3), pp.400-417.

Churchill, G.A. and Suprenant, C. (1982). "An Investigation Into the Determinants of Customer Satisfaction," Journal of Marketing Research, 19(4), pp.491-504.

Chin, W.W. (1998). "Issues and Opinion on Structural Equation Modeling," MIS Quarterly, 22(1), pp.7-16.

Constant, D., Kiesler, S. and Sproull, L. (1994). "What's Mine Is ours, or Is It? A Study of Attitude about Information Sharing," Information Systems Research, 5(4), pp.400-422.

Constantiou, I.D., Lehrer, C. and Hess, T. (2014). "Changing Information Retrieval Behaviors: An Empirical Investigation of Users' Cognitive Processes in the Choice of LocationBased Services," European Journal of Information Systems, 23(5), pp.513-528.

Crowne, D. P., and Marlowe, D. (1960). "A New Scale of Social Desirability Independent of Psychopathology," 
Journal of Consulting Psychology, 24(4) pp.349-354.

Daurer, S., Molitor, D., Spann, M. and Manchanda, P. (2013). "The Impact of Smartphones, Barcode Scanning, and Location-based Services on Consumers' Search Behavior," Proceedings of the International Conference on Information Systems, ICIS 2013, AIS 2013.

Davis, F.D. (1989). "Perceived Usefulness, Perceived Ease of Use, and User Acceptance of Information Technology," MIS Quarterly, 13(3), pp.319-340.

Davis, F.D., Bagozzi, R.P. and Warshaw, P.R. (1992). "Extrinsic and Intrinsic Motivation to Use Computers in the Workplace," Journal of Applied Social Psychology, 22(14), pp.1111-1132.

Dhar, S. and Varshney, U. (2011). "Challenges and Business Models for Mobile Location-based Services and Advertising," Communications of the ACM, 54(5), pp.121-128.

Dinev, T. and Hart, P. (2006). "An Extended Privacy Calculus Model for Ecommerce Transactions," Information Systems Research, 17(1), pp.61-80.

Eighmey, J. and McCord, L. (1998). "Adding Value in the Information Age: Uses and Gratifications of Sites on the World Wide Web," Journal of Business Research, 41(3), pp.187194.

Festinger, L. (1957). A Theory of Cognitive Dissonance. Row and Peterson: Evanston, IL.

Fornell, C. and Larcker, D.F. (1981). "Structural Equation Models with Unobservable Variables and Measurement Error: Algebra and Statistics," Journal of Marketing Research, 18(3), pp.382-388.

Fortin, D.R. and Dholakia, R.R. (2005). "Interactivity and Vividness Effects on
Social Presence and Involvement with a Web-Based Advertisement," Journal of Business Research, 58(3), pp.387-396.

Grejner-Brznezinska, D. and Kealy, A. (2013). "Positioning and Tracking Approaches and Technologies," in Karimi, H. A. (ed.), Advanced Location-Based Technologies and Services, Taylor \& Francis Group: Boca Raton, FL

Gruca, T.S. and Rego, L.L. (2005). "Customer Satisfaction, Cash Flow, and Shareholder Value," Journal of Marketing, 69(3), pp.115-130.

Hair, J.F. Jr. anderson, R.E., Tatham, R.L. and Black, W.C. (1998). Multivariate Data Analysis with Readings. Prentice Hall: Englewood Cliffs, NJ.

Hazas, M., Scott, J. and Krumm, J. (2004). "Location-aware Computing Comes of Age," IEEE Computer, 37(2), pp.95-97.

Hirsch, F., Kemp, J. and Ilkka, J. (2006). Mobile Web Services: Architecture and Implementation. John Wiley and Sons: Ltd Natick, England.

Hirschman, E.C. and Holbrook, M.B. (1982). "Hedonic Consumption: Emerging Concepts, Methods and Propositions," Journal of Marketing, 46(3), pp.92101.

Ho, S.Y. (2012). "The Effects of Location Personalization on Individuals' Intention to Use Mobile Services," Decision Support Systems, 53(4), pp.802-812.

Hong, S.-J. and Tam, K.Y. (2006). "Understanding the Adoption of Multipurpose Information Appliances: The Case of Mobile Data Services," Information Systems Research, 17(2), pp.162-179.

Jiang, Z. and Benbasat, I. (2007). "Investigating the Influence of the Functional Mechanisms of Online 
Product Presentations," Information Systems Research, 18(4), pp.454470.

Jiang, B. and Yao, X. (2006). "Locationbased Services and GIS in Perspective," Computers, Environment and Urban Systems, 30(6), pp.712-725.

Junglas, I.A. and Watson, R.T. (2008). " Location-based Service," Communication of the ACM, 51(3), pp.65-70.

Junglas, I.A., Johnson, N.A. and Spitzmuller, C. (2008). "Personality Traits and Concern for Privacy: An Empirical Study in The Context of Locationbased Services," European Journal of Information Systems, 17(4), pp.387-402.

Kleijen, M.A., Lievens, J.C., Ruyter, K.De. and Wetzels, M.G.M. (2009) " Knowledge Creation Through Mobile Social Networks and Its Impact on Intentions to Use Innovative Mobile Services," Journal of Service Research, 12(1), pp.15-35.

Kraut, R.E., Egido, C. and Galegher, J. (1990). "Patterns of Contact and Communication in Scientific Research Collaborations," In J. Galegher, R. E. Kraut, and C. Egido (eds.), Intellectual Teamwork, Social and Technological Foundations of Cooperative Work, Lawrence Erlbaum: Hillsdale, NJ.

Krishnamurthy, P. and Pelechrinis, K. (2013). "Location-Based Social Networks," in Karimi, H. A. (ed.), Advanced Location-Based Technologies and Services, Taylor \& Francis Group: Boca Raton, FL

Laufer, R.S. and Wolfe, M. (1997). "Privacy as $A$ Concept and A Social Issue: A Multidimensional Developmental Theory," Social Issues, 33(3), pp.2224.
Li, C. (2006). “User Preferences, Information Transactions and Location-based Services: A Study of Urban Pedestrian Wayfinding," Computers, Environment and Urban Systems, 30(6), pp.726-740.

$\mathrm{Li}$, C. and Longley, P.A (2006). "Test Environment for Location-based Services Applications," Transactions in GIS, 10(1), pp.43-61.

Liu, Y. and Shrum, L.J. (2002). "What Is Interactivity and Is It always Such a Good Thing? Implications of Definition, Person, and Situation for the Influence of Interactivity on Advertising Effectiveness," Journal of Advertising, 31(4), pp. 53-64.

Luo, X. and Bhattacharya, C.B. (2006). "Corporate Social Responsibility, Customer Satisfaction, and Market Value," Journal of Marketing, 70(4), pp.1-18.

McMillan, S.J. and Hwang, J.S. (2002). "Measures of Perceived Interactivity: An Exploration of the Role of Direction of Communication, User Control, and Times in Shaping Perceptions of Interactivity," Journal of Advertising, 31(3), pp.29-42.

Malhotra, N.K., Kim, S.S. and Agarwal, J. (2004). 'Internet Users' Information Privacy Concerns (IUIPC): The Construct, the Scale, and a Causal Model," Information Systems Research, 15(4), pp.336-355.

Marks, G. (2012). "Drilling Down: Small Businesses and Location-based Marketing," Retrieved from http://boss.blogs.nytimes.com/2012/0 4/16/drilling-down-small-businessesand-location-based-marketing/ on April 16, 2014.

Mathieson, K. (1991). "Predicting User Intentions: Comparing the Technology Acceptance Model with the Theory of Planned Behavior. 
Information Systems Research, 2(3), pp.173-191.

McKinney, V., Yoon, K. and Zahedi, F.M. (2002). "The Measurement of Webcustomer Satisfaction: An Expectation and Disconfirmation Approach," Information Systems Research, 13(3), pp.296-315.

Miller, C.C. and Wortham, J. (2010). "Technology Aside, Most People Still Decline to be Located," Retrieved from

http://www.nytimes.com/2010/08/30/t echnology/30location.html?pagewant ed=all\& $r=0$ on August 30, 2014.

Mohr, J. and Spekman, R. (1994). "Characteristics of Partnership Success: Partnership Attributes, Communication Behavior, and Conflict Resolution Techniques," Strategic Management Journal, 15(2), pp.135-152.

Mollen, A. and Wilson, H. (2010). "Engagement, Telepresence and Interactivity in Online Consumer Experience: Reconciling Scholastic and Managerial Perspectives," Journal of Business Research, 63(910), pp. 919-925.

Oliver, R.L. (1980). "A Cognitive Model of the Antecedents and Consequences of Satisfaction Decisions," Journal of Marketing Research, 17(4), pp.460469.

Oliver, R.L. (1997). "Satisfaction: a Behavioral Perspective on the Consumer. Irwin/McGraw-Hill: New York.

Oliver, R.L., Balakrishnan, P.V. and Barry, B. (1994). "Outcome Satisfaction in Negotiation: A Test of Expectancy Disconfirmation," Organizational Behavior and Human Decision Processes, 60(2), pp.252-275.

Oliver, R.L. and Westbrook, R.A. (1993). "Profiles of Consumer Emotions and Satisfaction in Ownership and
Usage," Journal of Consumer Satisfaction, Dissatisfaction and Complaining Behavior, 6(2), pp.12-27.

O'Reilly, C.A. and Chatman, J. (1986). "Organizational Commitment and Psychological Attachment: The Effects of Compliance, Identification, and Internalization on Prosocial Behavior," Journal of Applied Psychology, 71(3), pp.492-499.

Pantouvakis, A. and Lymperopoulos, K. (2008). "Customer Satisfaction and Loyalty in the Eyes of New and Repeat Customers: Evidence From the Transport Sector," Managing Service Quality, 18(6), pp.623-643.

Podsakoff, P.M., Mackenzie, S.B., Lee, J.Y. and Podsakoff, N.P. (2003). "Common Method Biases in Behavioral Research: A Critical Review of the Literature and Recommended Remedies," Journal of Applied Psychology, 88(5), pp.879-903.

Rao, B. and Minakakis, L. (2003). "Evolution of Mobile Location-based Services," Communication of the ACM, 46(12), pp.61-65.

Segars, A.H. (1997). "Assessing the Unidimensionality of Measurement: A Paradigm and Illustration within the Context of Information Systems Research," OMEGA, 25(1), pp.107121.

Sheng, H., Nah, F.F. and Siau, K. (2008). "An Experimental Study on Ubiquitous Commerce Adoption: Impact of Personalization and Privacy Concerns," Journal of the Association for Information Systems, 9(6), pp.344-376.

Spreng, R.A. and Chiou, J.S. (2002). "A Cross-cultural Assessment of the Satisfaction Formation Process," European Journal of Marketing, 36(7/8), pp.829-839. 
Spreng, R.A., MacKenzie, S.B. and Olshavsky, R.W. (1996). "A Reexamination of the Determinants of Consumer Satisfaction," Journal of Marketing, 60(3), pp.15-32.

Steenkamp, J.-P.E.M. and Geyskens, I. (2006). "How Country Characteristics Affect the Perceived Value of Web Sites," Journal of Marketing, 70(3), pp.136-115.

Steinfield, C. (2004). "The Development of Location Based Services in Mobile Commerce," In Preissl , B., Bouwman, $H$. and Steinfield, C. (eds.), E-Life after the Dot Com Bust, Springer: Heidelberg, Berlin.

Steuer, J. (1992). "Defining Virtual Reality: Dimensions Determining Telepresence," Journal of communication, 42(4), pp.73-93.

Suh, A., Shin, K.S., Ahuja, M. and Kim, M.S. (2011). "The Influence of Virtuality on Social Networks within and Across Work Groups: A Multilevel Approach," Journal of Management Information Systems, 28(1), pp.351-386.

Suikkola, V. (2010). "Open Exposure of Telco Capabilities Identification of Critical Success Factors for Locationbased Services in Open Telco," Proceedings of the 2010 6th International Conference on Wireless and Mobile Communications, IEEE Computer Society Washington.

Sultan, F. and Rohm, A.J. (2008). "How to Market to Generation Mobile," MIT Sloan management review, 49(4), pp.35-41.

Taylor, S. and Todd, P.A. (1995). "Understanding Information Technology Usage: A Test of Competing Models," Information Systems Research, 6(2), pp.144-176.

Thorson, K.S., Rodgers, S. (2006). "Relationships between Blogs as eWOM and Interactivity, Perceived Interactivity, and Parasocial
Interaction," Journal of Interactive Advertising, 6(2), pp.34-44.

Tse, D.K. and Wilton, P.C. (1988). "Models of Consumer Satisfaction: an Extension," Journal of Marketing Research, 25, pp.204-212.

Venkatesh, V. (2000). "Determinants of Perceived Ease of Use: Integrating Control, Intrinsic Motivation, and Emotion into the Technology Acceptance Model," Information Systems Research, 11(4), pp.342365.

Venkatesh, V. and Goyal, S. (2010). "Expectation Disconfirmation and Technology Adoption: Polynomial Modeling and Response Surface Analysis," MIS Quarterly, 34(2), pp.281-303.

Van Montfort, K., Masurel, E. and Van Rijn, I. (2000). "Service Satisfaction: An Empirical Analysis of Consumer Satisfaction in Financial Services," The Service Industries Journal, 20(3), pp. 80-94

Wang, S.C. and Wu, J.H. (2014). "Proactive Privacy Practices in Transition: Toward Ubiquitous Services," Information \& Management, 51(1), pp.93-103.

Wang, X. (2011). "The Effect of Unrelated Supporting Service Quality on Consumer Delight, Satisfaction, and Repurchase Intentions," Journal of Service Research, 14(2), pp.149-163.

Wortham, J. (2012). "New Apps Connect to Friends Nearby," Retrieved from http://www.nytimes.com/2012/03/09/t echnology/new-apps-connect-tofriends-nearby.html?pagewanted $=$ all on July 9, 2014.

Xu, H., Teo, H.H., Tan, B.C.Y. and Agarwal, R. (2009). "The Role of Push-pull Technology in Privacy Calculus: The Case of Location-based Services," Journal of Management Information Systems, 26(3), pp.135-173. 
Yu, J., Zo, H., Choi, M. K. and Ciganek, A.P. (2013). "User Acceptance of Location-Based Social Networking Services: An Extended Perspective of Perceived Value," Online Information Review, 37(5), pp.711730.

Zhang, Y., Fang, Y., Wei, K.K. and Chen, H. (2010). "Exploring the Role of Psychological Safety in Promoting the Intention to Continue Sharing Knowledge in Virtual Communities,"
International Journal of Information Management, 30(5), pp.425-436.

Zimmermann, A., Specht, M. and Lorenz, A. (2005). "Personalization and Context Management, "User Modeling and User-Adapted Interaction, 15(3), pp.275-302.

Zhou, T. (2013). "An Empirical Examination of User Adoption of Location-Based Services," Electronic Commerce Research, 13(1), pp.25-39. 


\section{Appendix I: Questionnaire Items}

\begin{tabular}{|c|c|c|c|}
\hline Constructs & ID & Items & Sources \\
\hline \multirow{4}{*}{$\begin{array}{l}\text { Perceived } \\
\text { usefulness }\end{array}$} & pu1 & Using SLBS improve my effectiveness in managing personal problems. & \multirow{4}{*}{ Bhattacherjee (2001) } \\
\hline & pu2 & Using SLBS increase my productivity in managing personal problems. & \\
\hline & pu3 & Using SLBS increase my productivity in finish tasks. & \\
\hline & pu4 & Overall, SLBS are useful and practical in managing personal problems. & \\
\hline \multirow{4}{*}{$\begin{array}{l}\text { Perceived } \\
\text { Interactivity }\end{array}$} & ia1 & SLBS provide me good interactivity. & \multirow{4}{*}{$\begin{array}{l}\text { Jiang and Benbasat (2007); } \\
\text { Animesh et al. (2011) }\end{array}$} \\
\hline & ia2 & SLBS can respond to my input effectively. & \\
\hline & ia3 & SLBS provide me a good channel to interact with my friends. & \\
\hline & ia4 & Based on each individual's preference, SLBS choose the display of target information. & \\
\hline \multirow{4}{*}{$\begin{array}{l}\text { Perceived } \\
\text { enjoyment }\end{array}$} & pe1 & I find using SLBS to be enjoyable. & \multirow{4}{*}{$\begin{array}{l}\text { Venkatesh (2000); } \\
\text { Hong and Tam (2006) }\end{array}$} \\
\hline & pe2 & The actual process of using SLBS is pleasant. & \\
\hline & pe3 & I have fun using SLBS. & \\
\hline & pe4 & I expect that using SLBS would be enjoyable. & \\
\hline \multirow{4}{*}{$\begin{array}{l}\text { Privacy } \\
\text { Concern }\end{array}$} & pe1 & I am concerned that the information I submit on SLBS could be misused. & \multirow{4}{*}{ Dinev and Hart (2006) } \\
\hline & pe2 & I am concerned that a person can find private information about me on SLBS. & \\
\hline & pe3 & I am concerned about submitting information on the SLBS, because of what others might do with it. & \\
\hline & pe4 & $\begin{array}{l}\text { I am concerned about submitting information on the SLBS, because it could be used in a way I did not } \\
\text { foresee. }\end{array}$ & \\
\hline \multirow{4}{*}{ Personalization } & ps1 & I expect that SLBS should provide me with personalized services tailored to my activity context. & \multirow{4}{*}{$\begin{array}{l}\text { Steenkamp and Geyskens } \\
\text { (2006); Xu et al. (2009) }\end{array}$} \\
\hline & ps2 & $\begin{array}{l}\text { I expect that SLBS should provide me with more relevant information tailored to my preferences or } \\
\text { personal interests. }\end{array}$ & \\
\hline & ps3 & I expect that SLBS should provide me with the kind of information or service that I might like. & \\
\hline & ps4 & I expect that SLBS should create the feeling of receiving personalized attention. & \\
\hline \multirow{4}{*}{$\begin{array}{l}\text { Information } \\
\text { sharing }\end{array}$} & $\operatorname{sh} 1$ & I expect that my sharing with other members should be an enjoyable experience. & \multirow{4}{*}{ Bock et al. (2005) } \\
\hline & sh2 & I expect that my sharing with other members should be valuable to me. & \\
\hline & sh3 & I expect that my sharing with other members should be good. & \\
\hline & sh4 & I expect that my sharing with other members should be a wise move. & \\
\hline \multirow{4}{*}{$\begin{array}{l}\text { SLBS } \\
\text { Confirmation }\end{array}$} & Ibsc1 & My experience with using SLBS was better than what I expected. & \multirow{4}{*}{$\begin{array}{l}\text { Bhattacherjee (2001); } \\
\text { Bhattacherjee } \\
\text { Premkumar (2004) }\end{array}$} \\
\hline & Ibsc2 & The service level provided by SLBS was better than what I expected. & \\
\hline & Ibsc3 & The ability of SLBS to enhance my effectiveness was much better than I expected. & \\
\hline & Ibsc4 & Overall, most of my expectations from using SLBS were confirmed. & \\
\hline \multirow{4}{*}{ Satisfaction } & sf1 & I am pleased with the overall SLBS. & \multirow{4}{*}{$\begin{array}{l}\text { Mathieson (1991); } \\
\text { Bhattacherjee } \\
\text { Premkumar (2004) }\end{array}$} \\
\hline & sf2 & Using SLBS is a delightful experience. & \\
\hline & sf3 & I am completely satisfied with the SLBS use experience. & \\
\hline & $\mathrm{sf4}$ & I am satisfied with my use of SLBS. & \\
\hline \multirow{2}{*}{$\begin{array}{l}\text { Continuance } \\
\text { use }\end{array}$} & ci1 & I have the intention to use SLBS in the future. & \multirow{2}{*}{$\begin{array}{l}\text { Taylor and Todd (1995); } \\
\text { Bhattacherjee }\end{array}$} \\
\hline & ci2 & I am willing to continue using SLBS in the future. & \\
\hline
\end{tabular}


Ho et al.: What Users Want: the Factors that Determine the Retention of Soci

What Users Want: the Factors that Determine the Retention of Social Location-Based Services/ Ho et al.

\begin{tabular}{|l|l|l|l|}
\hline \multirow{2}{*}{$\begin{array}{l}\text { Social } \\
\text { Desirability }\end{array}$} & I intend to use SLBS frequently in the future. & Premkumar (2004) \\
\hline & sd1 & I plan to continue using SLBS to solve my need related work and life. \\
\cline { 2 - 3 } & sd2 & I always try to practice what I preach. & Crowne and Marlowe (1960) \\
\cline { 2 - 3 } & sd3 & I never resent being asked to return a favor. \\
\cline { 2 - 3 } & sd4 & I have never been irked when people expressed ideas very different from my own. \\
\hline
\end{tabular}




\section{Appendix II: Variance-Covariance Matrix of Items}

\begin{tabular}{|c|c|c|c|c|c|c|c|c|c|c|c|c|c|c|c|c|c|c|c|c|c|c|c|c|c|c|c|c|c|c|c|c|c|c|c|c|c|c|c|c|}
\hline & & & & & & & & 4 & 11 & 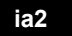 & & 14 & 11 & v2 & V3 & & & 58 & & & is1 & is2 & 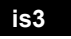 & . & & & & & st1 & $\mathbf{5 1 2}$ & STS & 14 & 11 & 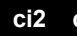 & 613 & $c 14$ & & & & \\
\hline 11 & 1.27 & 1.03 & 1.00 & .81 & .48 & .47 & 51 & .51 & 49 & 47 & 48 & 53 & .22 & .23 & .23 & 22 & .36 & 39 & .31 & 38 & .18 & 19 & 17 & 19 & .55 & .58 & .56 & .48 & .47 & 48 & .53 & .48 & .49 & 50 & .53 & 48 & .07 & .04 & .08 & 05 \\
\hline 42 & 1. & .21 & 1.02 & .86 & .47 & .48 & 53 & .50 & 50 & 48 & .49 & .52 & 4 & .21 & .23 & 22 & .38 & 38 & 32 & 37 & 19 & 18 & 19 & .18 & & & 54 & & 46 & 48 & .53 & 51 & .48 & 52 & 54 & 46 & 05 & 08 & 05 & b7 \\
\hline u3 & 1.00 & 02 & 1.25 & 83 & .48 & .48 & 51 & .48 & 48 & 48 & .51 & .50 & 2 & .22 & .23 & .22 & .39 & 38 & .29 & 38 & 18 & 17 & 19 & 19 & & & 55 & & .46 & .50 & .51 & 49 & .49 & 51 & .56 & .44 & 06 & 05 & .07 & 06 \\
\hline 44 & .81 & 86 & 83 & 1.04 & .41 & .40 & 45 & .43 & 43 & 38 & .45 & .45 & 8 & .18 & .20 & .20 & .32 & 31 & .30 & 32 & .16 & 16 & 15 & 16 & & & 43 & & .44 & 41 & .44 & 41 & .43 & 44 & .43 & 41 & 04 & 06 & .05 & 06 \\
\hline 11 & .48 & .47 & 48 & .41 & 1.09 & .84 & .86 & .78 & .51 & .48 & .49 & .52 & .14 & .10 & .15 & .14 & .30 & .28 & .24 & 29 & .24 & 23 & .23 & 23 & 5 & & .50 & & .55 & .53 & .59 & .54 & .47 & .48 & .49 & .43 & .06 & 05 & .04 & 04 \\
\hline 22 & .47 & .48 & 48 & .40 & .84 & 1.05 & .87 & .77 & .50 & .49 & .49 & .52 & .13 & .12 & .14 & .13 & .28 & .29 & .24 & 30 & .24 & .25 & .23 & 20 & 4 & & .5 & & .54 & .54 & .56 & .56 & .47 & .47 & .49 & .42 & .04 & .07 & .04 & .04 \\
\hline e3 & .51 & 53 & .51 & .45 & .86 & .87 & 1.22 & .94 & .54 & .50 & .58 & .57 & .14 & .15 & .15 & .14 & .33 & .31 & .28 & .28 & .25 & .23 & .25 & .28 & .55 & .5 & .5 & .4 & .57 & .60 & .63 & .59 & .49 & .52 & .55 & .47 & .03 & .04 & .06 & 08 \\
\hline 4 & .51 & 50 & 48 & 43 & .78 & .77 & .94 & 1.27 & .50 & .50 & .52 & .57 & .13 & .16 & .13 & .14 & .28 & .31 & .24 & .33 & .23 & .22 & .25 & .26 & .45 & .5 & .5 & .4 & .53 & .56 & .63 & .58 & .46 & .50 & .52 & .46 & .05 & .04 & .08 & 04 \\
\hline 11 & .49 & .50 & .48 & .43 & .51 & .50 & .54 & .50 & 1.14 & .79 & .79 & .81 & .16 & .13 & .16 & .18 & .35 & .35 & .30 & .35 & .26 & .25 & .24 & .29 & $.4 \varepsilon$ & .5 & .4 & .46 & .47 & .44 & .47 & .43 & .43 & .43 & .44 & .39 & .10 & .09 & .06 & 07 \\
\hline 22 & .47 & 48 & .48 & .38 & .48 & .49 & .50 & .50 & .79 & 1.08 & .74 & .78 & .16 & .15 & .16 & .14 & .32 & .33 & .32 & .33 & .23 & .25 & .25 & .27 & .5 & .5 & .5 & .44 & .42 & .41 & .47 & .44 & .40 & .42 & .42 & .38 & .07 & .08 & .06 & 09 \\
\hline a3 & .48 & 49 & .51 & .45 & .49 & .49 & .58 & .52 & .79 & .74 & 1.19 & .89 & .16 & .16 & .17 & .15 & .38 & .36 & .29 & .33 & .26 & .26 & .26 & .26 & .4 & .4 & .5 & .4 & .42 & .46 & .47 & .48 & .41 & .44 & .47 & .41 & .05 & .07 & .11 & 11 \\
\hline a4 & .53 & .52 & .50 & 45 & .52 & .52 & .57 & .57 & .81 & .78 & .89 & 1.28 & .15 & .19 & .17 & .16 & .36 & .38 & .29 & .40 & .30 & .27 & .29 & .25 & .55 & .5 & .5 & .4 & .45 & .47 & .52 & .48 & .44 & 46 & .49 & .41 & .08 & .09 & .12 & 06 \\
\hline v1 & .22 & .24 & .22 & . 18 & .14 & .13 & .14 & .13 & . 16 & .16 & .16 & .15 & 1.25 & 1.03 & 1.01 & .96 & .22 & .21 & .18 & 18 & .05 & .02 & .04 & .06 & .1 & .1 & .1 & .1 & .09 & . 10 & .10 & .07 & .13 & 15 & .16 & 15 & .04 & 03 & .03 & 02 \\
\hline v2 & .23 & .21 & .22 & .18 & 10 & .12 & 15 & .16 & .13 & .15 & .16 & .19 & 1.03 & 1.23 & 1.01 & .94 & .23 & 19 & .16 & .20 & .03 & .04 & .04 & .07 & .1 & .1 & .1 & .1 & .10 & . 10 & .09 & .08 & .15 & 15 & .16 & .13 & .01 & 03 & .05 & 03 \\
\hline v3 & .23 & .23 & .23 & .20 & 15 & .14 & .15 & .13 & . 16 & .16 & .17 & .17 & 1.01 & 1.01 & 1.37 & 1.12 & .19 & .24 & 17 & .23 & .05 & .07 & .05 & .02 & .1 & .1 & .1 & .1 & .08 & .08 & .12 & 11 & .15 & . 16 & .17 & .14 & .02 & 02 & .04 & 04 \\
\hline v4 & .22 & .22 & .22 & .20 & .14 & .13 & .14 & .14 & .18 & .14 & .15 & .16 & .96 & .94 & 1.12 & 1.33 & .20 & .19 & 19 & .22 & .06 & .04 & .05 & .03 & .1 & .1 & 13 & .1 & .09 & .09 & .08 & 11 & .16 & . 15 & .16 & .13 & .05 & 03 & .01 & 03 \\
\hline 51 & .36 & .38 & 39 & .32 & .30 & .28 & .33 & .28 & 35 & .32 & .38 & .36 & .22 & .23 & .19 & .20 & 1.17 & .81 & .60 & .73 & .17 & .12 & .16 & 17 & .31 & .3 & .2 & .31 & .34 & .34 & .37 & .34 & .28 & .30 & .28 & .25 & .04 & 08 & .07 & 01 \\
\hline 52 & .39 & 38 & .38 & 31 & .28 & .29 & .31 & .31 & .35 & .33 & .36 & .38 & .21 & .19 & .24 & .19 & .81 & 1.07 & .65 & .75 & .15 & .15 & .17 & .15 & .3 & .3 & .3 & .29 & .34 & .32 & .37 & .36 & .27 & .28 & .32 & .24 & .06 & 55 & .09 & 05 \\
\hline 33 & .31 & 32 & 29 & .30 & .24 & .24 & .28 & .24 & .30 & .32 & .29 & .29 & 18 & .16 & .17 & .19 & .60 & .65 & .90 & .61 & .11 & .15 & .13 & .13 & .2 & .3 & .2 & .25 & .29 & .32 & .29 & .27 & .23 & .22 & .24 & .25 & 05 & 06 & .05 & 06 \\
\hline 54 & .38 & .37 & .38 & .32 & .29 & .30 & .28 & .33 & 35 & .33 & .33 & .40 & .18 & .20 & .23 & .22 & .73 & .75 & .61 & 1.25 & .17 & 17 & .12 & . 16 & 3 & .3 & .3 & . 2. & .31 & 32 & .39 & .36 & .28 & .29 & .30 & .25 & .08 & .05 & .05 & .07 \\
\hline 11 & .18 & 19 & .18 & 16 & .24 & .24 & .25 & .23 & .26 & .23 & .26 & .30 & .05 & .03 & .05 & .06 & .17 & .15 & .11 & .17 & 1.25 & .93 & .92 & .95 & .24 & .2 & .2 & .2 & .38 & 38 & .38 & .38 & .39 & 41 & .44 & .37 & .18 & 18 & 18 & 19 \\
\hline 2 & .19 & 18 & 17 & . 16 & .23 & .25 & .23 & .22 & .25 & .25 & .26 & .27 & .02 & .04 & .07 & .04 & .12 & .15 & .15 & .17 & .93 & 1.15 & .93 & 92 & .25 & .2 & .2 & .21 & .36 & 36 & .39 & 36 & .40 & 39 & 40 & .37 & 17 & 14 & .21 & 20 \\
\hline s3 & .17 & 19 & 19 & 15 & .23 & .23 & .25 & .25 & .24 & .25 & .26 & .29 & .04 & .04 & .05 & .05 & .16 & .17 & .13 & .12 & .92 & .93 & 1.19 & .95 & .2 & .2 & .2 & .24 & .35 & .38 & .40 & .37 & .38 & 42 & 43 & .35 & 16 & 20 & .22 & .15 \\
\hline s4 & .19 & .18 & 19 & .16 & .23 & .20 & .28 & .26 & .29 & .27 & .26 & .25 & .06 & .07 & .02 & .03 & .17 & .15 & .13 & .16 & .95 & .92 & .95 & 1.32 & .2 & .28 & .2 & .22 & .36 & .36 & .42 & .39 & .39 & 42 & .43 & .39 & 16 & 21 & .11 & .21 \\
\hline lbsc & .55 & .55 & .52 & .45 & .50 & .49 & .55 & .49 & .48 & .51 & .49 & .55 & .15 & .15 & .12 & .11 & .31 & .30 & .28 & 33 & .24 & .25 & .26 & .27 & 1.23 & 1.09 & .9 & .83 & .61 & .63 & .68 & 3 & .45 & .45 & .46 & .44 & 05 & 3 & .06 & $0 /$ \\
\hline Ibsc2 & .58 & .57 & .55 & .46 & .52 & .52 & .55 & .54 & .54 & .54 & .47 & .56 & .16 & .15 & .13 & .13 & .30 & .33 & .30 & .34 & .27 & .27 & .25 & .28 & 1.09 & 1.32 & 1.0 & .8 & .65 & .65 & .71 & 6 & .47 & 47 & .50 & .44 & .08 & 4 & 03 & 00 \\
\hline Ibsc3 & .56 & .54 & .55 & .43 & .50 & .50 & .51 & .53 & .48 & .50 & .50 & .56 & .15 & .12 & .15 & .13 & .29 & .32 & .25 & .37 & .24 & .26 & .25 & .28 & .9 & 1.04 & 1.4 & .8 & .58 & 62 & .11 & .65 & .46 & .45 & .51 & 39 & .07 & 03 & .07 & 03 \\
\hline Ibsc4 & .48 & .47 & .46 & .43 & .43 & .44 & .49 & .44 & .46 & .44 & .43 & .47 & .13 & .11 & .11 & .13 & .31 & .29 & .25 & .22 & .23 & .21 & .24 & .22 & .83 & .87 & .8 & 1.05 & .58 & .54 & .59 & .56 & .38 & .42 & 41 & .38 & .04 & 05 & .06 & 03 \\
\hline ff1 & .47 & .46 & .46 & .44 & .55 & .54 & .57 & .53 & .47 & .42 & .42 & .45 & .09 & .10 & .08 & .09 & .34 & .34 & .29 & 31 & .38 & .36 & .35 & .36 & .61 & 6 & .5 & .58 & 1.08 & .87 & .90 & .84 & .68 & 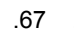 & .69 & .63 & .03 & 02 & .02 & .03 \\
\hline st2 & .48 & .48 & .50 & .41 & .53 & .54 & .60 & .56 & .44 & .41 & .46 & .47 & .10 & .10 & .08 & .09 & .34 & .32 & .32 & .32 & .38 & .36 & .38 & .36 & .6 & .6 & .6 & .54 & .87 & 1.09 & .92 & .86 & 66 & .69 & .73 & .63 & .04 & 02 & .03 & .02 \\
\hline $\mathrm{f} 3$ & .53 & 53 & .51 & .44 & .59 & .56 & .63 & .63 & .47 & .47 & .47 & .52 & .10 & .09 & .12 & .08 & .37 & .37 & .29 & .39 & .38 & .39 & .40 & .42 & 6 & .7 & - & .59 & .90 & .92 & 1.26 & 98 & .71 & .76 & .79 & .67 & 02 & J3 & .02 & .04 \\
\hline$f 4$ & .48 & .51 & .49 & .41 & .54 & .56 & .59 & .58 & .43 & .44 & .48 & .48 & .07 & .08 & .11 & .11 & .34 & .36 & .27 & .36 & .38 & .36 & .37 & .39 & .6 & .6 & .6 & .56 & .84 & .86 & .98 & 1.14 & .67 & .72 & .76 & .63 & .01 & 04 & 05 & . 01 \\
\hline i1 & .49 & .48 & .49 & .43 & . 47 & .47 & .49 & .46 & .43 & .40 & .41 & .44 & .13 & .15 & .15 & .16 & .28 & .27 & .23 & .28 & .39 & .40 & .38 & .39 & & .4 & .46 & .38 & .68 & .66 & .71 & .67 & 1.16 & 1.041 & 1.02 & .89 & 03 & 01 & 04 & .04 \\
\hline i2 & .50 & .52 & .51 & .44 & . .48 & .47 & .52 & .50 & .43 & .42 & .44 & 46 & .15 & .15 & .16 & .15 & .30 & .28 & .22 & .29 & .41 & .39 & .42 & .42 & & .4 & .4 & .4 & .67 & .69 & .76 & .72 & 1.04 & 1.23 & 1.10 & .92 & 03 & 05 & 03 & . 01 \\
\hline i3 & .53 & .54 & .56 & .43 & .49 & .49 & .55 & .52 & .44 & .42 & .47 & .49 & .16 & .16 & .17 & .16 & .28 & .32 & .24 & .30 & .44 & .40 & .43 & .43 & & .5 & .5 & .4 & .69 & .73 & .79 & . 76 & 1.02 & 1.10 & 1.42 & .96 & .04 & 06 & .02 & .00 \\
\hline i4 & .48 & .46 & .44 & .41 & .43 & .42 & .47 & .46 & .39 & .38 & .41 & .41 & .15 & .13 & .14 & .13 & .25 & .24 & .25 & .25 & .37 & .37 & .35 & .39 & & .4 & .3 & .38 & .63 & .63 & .67 & .63 & .89 & .92 & .96 & 1.11 & .01 & .00 & .04 & .07 \\
\hline d1 & .07 & .05 & .06 & .04 & .06 & .04 & .03 & .05 & 10 & .07 & .05 & .08 & .04 & .01 & .02 & .05 & .04 & .06 & .05 & .08 & .18 & .17 & .16 & 16 & & 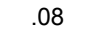 & .0 & .0 & .03 & .04 & .02 & .01 & .03 & .03 & .04 & .01 & .95 & 67 & 64 & .60 \\
\hline d2 & .04 & .08 & .05 & .06 & .05 & .07 & .04 & .04 & .09 & .08 & .07 & .09 & .03 & .03 & .02 & .03 & .08 & .05 & .06 & .05 & .18 & .14 & .20 & .21 & .03 & .0 & .0 & .05 & .02 & .02 & .03 & .04 & .01 & 05 & .06 & .00 & 67 & 1.05 & $\begin{array}{ll}5.70 \\
\end{array}$ & .62 \\
\hline d3 & .08 & .05 & .07 & .05 & .04 & .04 & .06 & .08 & .06 & .06 & .11 & 12 & .03 & .05 & .04 & .01 & .07 & .09 & .05 & .05 & .18 & 21 & .22 & . 17 & .06 & .03 & .07 & .06 & .02 & .03 & .02 & .05 & .04 & 03 & .02 & .04 & 64 & .70 & 1.30 & .79 \\
\hline 04 & .05 & .07 & .06 & .06 & .04 & .04 & .08 & .04 & .07 & .09 & .11 & .06 & .02 & .03 & .04 & .03 & .07 & .05 & .06 & .07 & .19 & .20 & .15 & .21 & .01 & .06 & .03 & .03 & .03 & .02 & .04 & .01 & .04 & .01 & .00 & .07 & .60 & 62 & .79 & 1.24 \\
\hline
\end{tabular}




\section{About the Authors}

Shu-Chun Ho is an associate professor of the Graduate Institute of Information and Computer Education at National Kaohsiung Normal University in Taiwan. Her research interests include user behaviors, mobile technology, and social media. She has published her work in the International Journal of Electronic Commerce, Electronic Commerce Research and Applications, and Information Technology and Management.

Jian-Liang Chen is an associate professor of the Department of Information Management at National Penghu University of Science and Technology in Taiwan. He specializes in information services and strategic management with a particular interest in user behaviors, e-learning, and strategic information systems. His studies on related research topics had been published in the International Journal of Human-Computer Studies, Computers in Human Behavior, International Journal of Information Management, Information \& Management, Computers \& Education, and other international journals.

Sheng-Tsz Luo is currently a programmer at Mostwant Technology in Taiwan. He graduated from the Graduate Institute of Information and Computer Education at National Kaohsiung Normal University. 